\title{
Gender and Race Differences in Pathways Out of In-Work Poverty in the US
}

\author{
Emanuela Struffolino ${ }^{1}$ and Zachary Van Winkle ${ }^{2}$
}

\begin{abstract}
Research on in-work poverty has focused on the probability of being employed while living in an impoverished household, but no studies have investigated pathways of labor market attachment and economic vulnerability following in-work poverty. We use the Panel Study of Income Dynamics (PSID) to establish a typology of employment pathways out of in-work poverty and to estimate differences by gender and race. By using the Sequence Analysis Multistate Model procedure, we identify five distinct pathways characterized by varying degrees of labor market attachment, economic vulnerability, and volatility. White men are most likely exit in-work poverty into stable employment outside of poverty, while Black men and women often experience recurrent spells of in-work poverty. Gender and race differences persist even after controlling for labor market and family demographic characteristics. Our results indicate that work-related anti-poverty strategies must be coupled with adequately high wages and employment protection legislation to effectively raise working households out of poverty.
\end{abstract}

Keywords: Gender, Race, In-Work Poverty, Sequence Analysis, Event History Analysis, Life Course

Accepted for publication, to be cited as: Emanuela Struffolino and Zachary Van Winkle (2021) Family demographic processes and in-work poverty: A systematic review, Social Science Research, Volume 99, September 2021, 102585, https://doi.org/10.1016/j.ssresearch.2021.102585

(C) The Authors 2022 - This accepted manuscript is distributed under the terms of the Creative Commons Attribution-NonCommercial-NoDerivatives 4.0 (CC BY-NC-ND 4.0) International Public License https://creativecommons.org/licenses/by-nc-nd/4.0/)

\section{Acknowledgments}

We thank the two anonymous reviewers and the participants of the joint writing workshop WZB/Humboldt University of Berlin and to the Sociology Postdoc Writing Workshop at Nuffield College at the University of Oxford for insightful comments and suggestions. We are grateful to David Brady and Ulrich Kohler for sharing the WZB-PSID code for PSID data preparation. This project has received funding from the European Union's Horizon 2020 research and innovation programme under grant agreement No. 681546 (FAMSIZEMATTERS) and from the Oxford/Berlin Research Partnership seed grant "Understanding Family Demographic Processes \& In-Work Poverty in Europe How Marriage, Parenthood, and Divorce Affect the Risk of In-work Poverty across the Life Course", grant number OXBER_SOC8.

\footnotetext{
${ }^{1}$ Corresponding author: University of Milan and Humboldt-Universität zu Berlin, Department of Social and Political Sciences, Via Conservatorio 7, Milan 20122, Italy, emanuela.struffolino@unimi.it

${ }^{2}$ Sciences Po and Nuffield College, Observatoire Sociologique du Changement 27 Rue Saint-Guillaume 75337, Paris Cedex 07 France, zachary.vanwinkle@sciencespo.fr
} 


\section{INTRODUCTION}

The working poor, employed individuals who live in households with incomes below the poverty threshold, represent a worrisome phenomenon that can engender social exclusion (Brady, Fullerton, and Moren Cross 2010). This is especially the case for individuals and households for which in-work poverty represents a long-lasting condition. For others, inwork poverty can be a short and sporadic event along pathways in stable and gainful employment or be characterized by multiple, recurring spells of unemployment or vulnerable employment. However, no studies have investigated pathways of labor market attachment and economic vulnerability following in-work poverty as they unfold over time.

Despite the necessity to account for the temporal dynamics of in-work poverty, most research is cross-sectional and either studied the association between in-work poverty and individual characteristics, such as education, gender and race, or macro-level factors, such as union density or welfare state generosity (see Kenworthy and Marx [2018] for a review). The few longitudinal accounts of in-work poverty studied the probability of entering and exiting the working poor as a function of changes in employment status and family structure across the life course (Hick and Lanau 2018; Barbieri, Cutuli, and Scherer 2018; Gutiérrez, Ibáñez, and Tejero 2011; Tejero 2017; Van Winkle and Struffolino 2018). Yet no research to date has analyzed individuals' pathways after exiting in-work poverty. Specifically, whether individuals escape in-work poverty through higher incomes or by exiting the labor market as well as how long individuals manage to escape in-work poverty remains unknown.

We address two research questions in this study: First, what pathways out of in-work poverty exist in the United States? We define individuals as being in in-work poverty if a) they have been employed at least an average of 20 hours per week in the course of the year and b) live in a household with a total household income under the poverty threshold. Pathways out of 
in-work poverty are therefore defined as a longitudinal sequence of individual labor market attachment and household economic wellbeing after individuals exit in-work poverty. Our focus then lies on individuals who both find themselves in in-work poverty and escape inwork poverty through a reduction in labor market attachment or an increase in economic wellbeing. To this end, we develop a framework for conceptualizing longitudinal dynamics of pathways out of in-work poverty that encompass varying degrees of labor market attachment, economic vulnerability, and volatility over time. It is crucial to understand how individuals exit in-work poverty for both theory and praxis.

Second, are pathways out of in-work poverty stratified by gender and race? In-work poverty rates vary considerably across gender and race groups (BLS 2018). Since the 1980s the proportion of employed white men and women in poverty ranged between three and five percent. In contrast, the percentage of working Black and Hispanic men and women living in impoverished households was higher and more varied more over time. In-work poverty rates fluctuated between four and thirteen percent for Black and Hispanic men, and between seven and sixteen percent for Black and Hispanic women. Differences in human capital and family demographic behavior, as well as labor market discrimination have all been put forward as possible explanations for these differences in the social stratification literatures.

Our analysis is the first substantive application of a novel methodological approach that enhances our understanding of how time-constant and time-varying individual and household characteristics are associated with different sequences of events following transitions out of in-work poverty across the life course. The Sequence Analysis Multistate Model (SAMM) procedure (Studer et al. 2018) brings together two methodological traditions in life course sociology: sequence analysis for the study of life course patterns as they unfold over time and event history analysis for the study of life course transitions. To construct and analyze 
employment and economic wellbeing trajectories following in-work poverty spells, we use the Panel Study of Income Dynamics (PSID).

\section{CONCEPTUALIZING PathWAys OUT OF IN-Work POVERTy}

Poverty is generally defined as having a household income below a certain threshold: for absolute poverty, that threshold is calculated on the basis of the amount of resources to guarantee access to basic needs; for relative poverty the threshold is set at $60 \%$ of the median of the household income distribution. While the absolute measure captures extreme poverty, the relative one identifies relative material deprivation. ${ }^{1}$ By extension, research on in-work poverty have adopted these definitions focusing on employed individuals. In this study, we use both definitions to account for degrees of economic vulnerability: in-work poverty is identified using the absolute threshold, while being at-risk-of-poverty using the relative one.

In this section, we conceptualize exits out of in-work poverty in terms of varying degrees of labor market attachment, economic vulnerability, and volatility that unfold over time. First, we briefly review a shift that took place in poverty research analyzing the risk of poverty from cross-sectional to life course approaches that stress temporal dynamics. We then discuss recent research on in-work poverty that adopted a life course approach. Finally, we extend the dichotomous conceptualization of being "working poor" or "not working poor" to account for changes in labor market attachment and economic hardship. This enables us to develop a typology that highlights alternative possible pathways out of in-work poverty.

\section{A Life Course Approach to In-Work Poverty}

1 The literature on poverty distinguishes between indicators that are either objective or subjective and either monetary or non-monetary. While each of these measures has advantages and disadvantages, in-work poverty measures commonly rely on monetary objective indicators. 
Rowntree (1901) recognized over a century ago that poverty should be studied longitudinally as it emerges and persists at different stages of the life course. Classical scholarship on poverty incorporated time as crucial dimension (Bane and Ellwood 1986; Duncan et al. 1993) and demonstrated that poverty is located in time and individual biographies (Leisering and Leibfried 1999): when poverty occurs along individual life courses has crucial consequences in terms of persistence in economic deprivation or opportunity to escape it for in the short and terms. Recent studies adopt a life course approach and analyze trajectories of economic wellbeing by considering how the welfare state, the market, and the family locate individuals in social groups across the life course (Dewilde 2003). This approach stresses the importance of studying poverty longitudinally as stratification occurs not only between but within individual life courses and that it is essential to analyze trajectories of economic wellbeing as they unfold over time (Daly 2018; Sandoval, Rank, and Hirsch 2009; Settersten and Mayer 1997). However, most of the existing longitudinal studies analyzed only the risk and the timing of entering and exiting poverty over a given observational window and attributed permanent or recurrent poverty spells to durable individual and household characteristics or to state dependence (Biewen 2009; Cappellari and Jenkins 2004).

This shift towards a life course approach to poverty is also evident in a few recent scholarly research focusing on in-work poverty. Van Winkle and Struffolino (2018) showed that the association between family demographic transitions in the US (e.g. marriage and divorce) and the probability of in-work poverty vary across the life course. Giesselmann (2015) found that although in-work poverty is more common among workers entering the labor market in Germany, those at later stages of their career are more susceptible in the UK. Vandecasteele and Gieselmann (2018) concluded after estimating the risk of entering and exiting in-work poverty in the UK that being working poor is transitory and occurs at specific phases of the life course. 
While important, these few studies did not go beyond estimating the risk of entering and exiting in-work poverty. However, focusing solely on the risk of entering or exiting in-work poverty masks important elements of in-work poverty dynamics. Adopting the dichotomous definition-“working poor" versus "working non-poor"- only allows researchers to identify patterns of cyclical in-work poverty. In contrast, linking different degrees of income vulnerability to labor market attachment allows researchers to consider intermediate circumstances. For example, exiting from in-work poverty may be driven by changes in employment status (from employment to unemployment) or by a moderate increase in income that is not sufficient to guarantee social inclusion and keep individuals and households at risk-of-poverty.

\section{Pathways Out of In-Work Poverty}

To account for longitudinal dynamics of pathways out of in-work poverty we extend previous propositions (Filandri and Struffolino 2013; Vandecasteele and Giesselmann 2018) by defining a typology of states that combines individual labor market status (being employed or not) and varying degrees of household economic hardship. The first study problematizes the ambivalent role of the household in buffering or driving in-work poverty non-working episode: individuals can be income-poor but live in non-poor households and vice-versa. The second study distinguished between poor and non-poor household and working and nonworking individuals. In both cases, typologies for studying in-work poverty longitudinally must consider different configurations of employment status and economic well-being as they occur over time depending on changes at the individual and the household level, respectively. Individual labor market participation and resources (of different kinds) redistributed within the household are-together to the welfare state-the main channels guaranteeing social 
inclusion, which is understood as not being in a state of severe material deprivation (Eurostat 2018). Because configurations of individual labor market participation and household income changes over time, social inclusion is a process that unfolds over the life course (Atkinson 1998; Negri and Saraceno 2000; Paugam 1998).

To account for these temporal dynamics and to understand their link with pathways out of inwork poverty, we propose the typology displayed in Figure 1: we identify conceptual states at the intersection of individual labor market status (working or non-working) and household economic status (being in absolute poverty, in relative poverty, or non-poor): individuals can move from one state to another over time depending on changes in own position in the labor market or in household income. We advance previous propositions by conceptualizing the degree of economic wellbeing beyond a binary definition of poor versus non poor. We use absolute poverty to identify a condition of severe economic deprivation: individuals are working poor if they are employed but their household income is not sufficient to fulfil basic needs (see data and methods below). In this sense, (in-work) poverty in Figure 1 reflects a more severe state of (in-work) poverty than is common in many studies on the subject.

Our study focuses on pathways out of in-work poverty, which can be initiated by a change in household economic wellbeing (vertical dimension in Figure 1), a change in individual labor market attachment (horizontal dimension in Figure 1), or both. First, an individual can exit in-work poverty through an improvement in economic wellbeing. Depending on the extent of this improvement, households are either lifted well above the poverty line so that they become non-poor and achieve a state of social inclusion or households can move to an intermediate state and remain at-risk of poverty. We use relative poverty to identify a condition of not having sufficient resources to afford those goods and life-styles above the basics that most people take for granted in a given context (see data and methods below). The use of absolute and relative poverty to classify individuals a poor or at-risk of poverty allows 
us to be more nuanced in conceptualizing economic pathways out of in-work poverty. Moreover, it is important to differentiate between non-poor and at-risk of poverty, because exiting severe poverty while continuing to lack the resources needed to enjoy the living standards of a given society not only keeps individuals and households in a vulnerable condition, but also inhibits individuals and households from recovering further (Spini, Bernardi, and Oris 2017).

Second, exiting in-work poverty can occur through the transition to unemployment. Depending on whether the household remains poor (in absolute poverty) or at-risk of poverty (in relative poverty) if other household member enters the labor market, individuals can slip into a state of social exclusion or at-risk of social exclusion, respectively. This latter intermediate state of living in a household at-risk of poverty while being unemployed also represents a vulnerable condition that increases the risk of social exclusion as both channels of social inclusion (employment and household resources) are absent or compromised. However, it is possible for non-employed individuals to enter a condition of full social inclusion if household economic status is lifted above the relative poverty line. 
Figure 1: Conceptual States Configuration by Study Measurements of Individual Labor

Market Status \& Household Economic Status

Individual

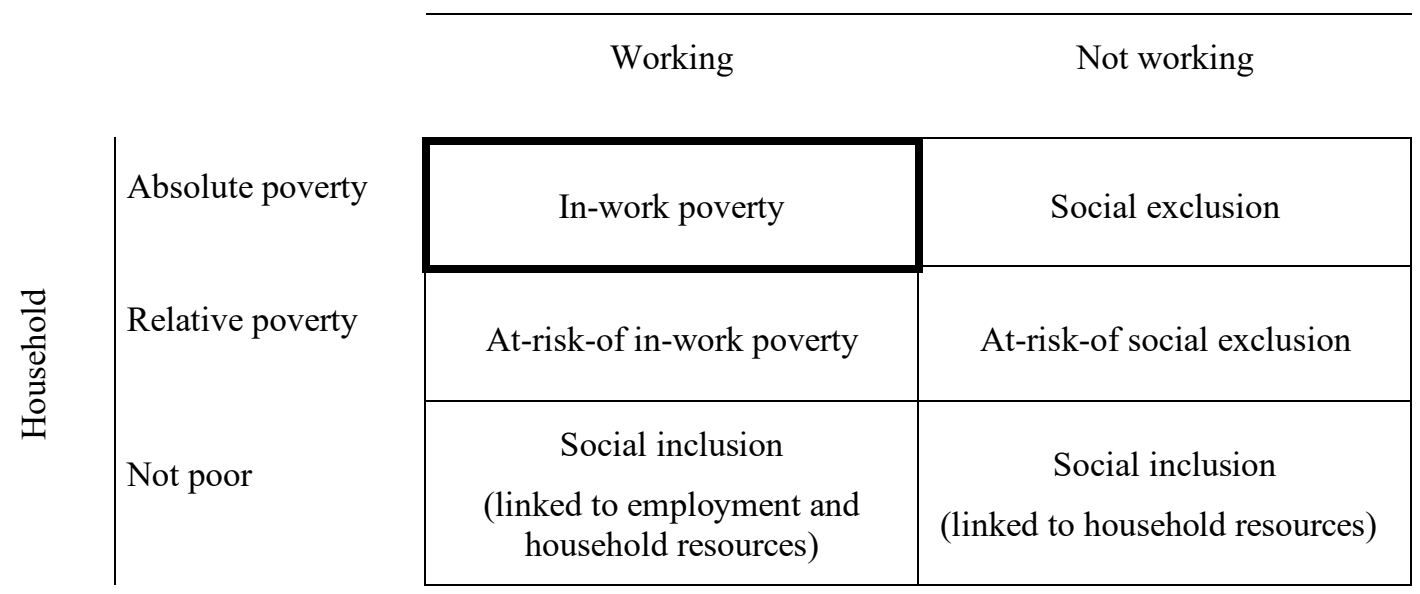

Note: Adapted and extended from Filandri and Struffolino (2013) and Vandecasteele and Gieselmann (2018).

Based on Figure 1, more or less advantageous pathways out of in-work poverty are predictable, however not all may be represented empirically. Some pathways may be characterized by stability in one state. For example, individuals may exit in-work poverty into a state of long-lasting social inclusion due to increased economic wellbeing within employment. Alternatively, a more disadvantageous pathway via a stable exit from in-work poverty may end in a stable state of social exclusion if individuals exit the labor market while remaining poor. Some pathways out of in-work poverty may be volatile and consist of multiple transitions between several states in the mid-term that expose individuals and households to risk of social exclusion and vulnerability. Additionally, precarious pathways out of in-work poverty may lead to stability within non-poor employment after having been at risk of poverty for a number of years but may also lead back to in-work poverty within a short time. 


\section{Pathways Out of IN-Work POVERTy By Gender AND RACE}

In this section, we elaborate on how and why pathways out of in-work poverty may differ by gender and race. We focus on these two factors, because they are arguably two of the most important for social stratification in the US. There are three main reasons to expect pathways out of in-work poverty to vary systematically by gender and race: differences in labor market resources, differences in family demographic behavior, and labor market discrimination.

The first two mechanisms - labor market resources and family demographic behavior - stem from behavioral theoretical explanations of poverty (see Brady [2018] for a review). The first mechanism refers to the accumulation of resources that are associated with employment over time, while the second associates poverty to entering or exiting cohabitation or marriage and the transition to parenthood. Labor market resources and family demographic behaviors are linked to the labor market opportunity structures individuals find themselves in as well as the probability of entering and exiting poverty within those labor market opportunity structures. In sum, different configurations of the labor market opportunity structure as emerging from the combination of individual resources and family demographic behavior generate varying degrees of labor market attachment and economic vulnerability. These latter can be considered as the drivers for individual differences in pathways out of in-work poverty.

The first behavioral approach links poverty with resources that individuals command to avoid labor market disadvantage: educational attainment, occupational position, and work experience. In the US, individuals with fewer labor market resources were more likely to regress into poverty or had difficulties re-entering the labor market after exiting it (Daly and Valletta 2006). Further individuals in lower skilled occupational groups were more likely to experience unemployment and those with more employment interruptions were less likely to be re-hired (Gangl 2004). Average differences in the level of labor market resources could generate gender and racial disparities in pathways out of in-work poverty. Blacks and 
Hispanics were less educated than whites individuals, held more precarious jobs, and had less high-quality work experience (Ryan and Siebens 2012), which decreased their chances to leave in-work poverty successfully.

Men were more educated than women were during the mid- $20^{\text {th }}$ century, although the education gender gap has tightened and even reversed in recent decades. Nonetheless, women's educational advantage did not translate into labor market advantages (England, Gornick, and Fitzgibbons 2012). In a recent study, Chudnovskaya and Kashyap (2019) demonstrate that men out-earn women even in educational and occupational hypogamous partnerships. Therefore, women may continue to experience more disadvantageous pathways out of in-work poverty. Men remain more likely to find employment in stable and secure occupations, while women do not participate on the labor market or find employment in occupational groups characterized by high turnover or (Reid and Rubin 2003). This is especially the case for Black and Hispanic women, who were more likely to experience low prestige careers often interrupted by unemployment and inactivity (Silke Aisenbrey and Fasang 2017).

The second behavioral approach links poverty to family demographic behavior: leaving the parental home, entering parenthood, and union formation and dissolution. While marriage had a protective function and shielded individuals from in-work poverty, separation and entering parenthood increased the risk of in-work poverty (Thiede et al. 2018; Van Winkle and Struffolino 2018). Leaving the parental home was a poverty-risk factor, due to the scarce amount of resources that were available when young adults transitioned onto the labor market (Aassve et al. 2007). Fertility transitions as well as union formations and dissolutions affected both the number of potential earners in the household, but also the economic needs of households (Uunk 2004). Average differences in family demographic behavior may produce gender and race disparities in pathways out of in-work poverty. Compared to whites, Black 
men and women were more likely to leave the parental home early, enter parenthood early and outside of marriage (Sweeney and Raley 2014), as well as form and dissolve a marital union compared to whites (Bulanda and Brown 2007; Sweeney and Phillips 2004). As for gender, Van Winkle and Struffolino (2018) showed that marriage had a protective function against in-work poverty only for women, while separation increased it across the life course. Parenthood was instead positively associated with in-work poverty mostly for women at early stages of the transition to adulthood.

Finally, an important mechanism that could lead to gender and race differences in pathways out of in-work poverty is discrimination on the labor market. Conscious and unconscious employer stereotypes translate into a lower probability to be hired and promoted as well as lower wages for women compared to men as well as for Blacks and Hispanics compared to whites (e.g., Jarrell and Stanley 2004; Bertrand and Mullainathan 2004). For example, employers may favor men over women when selecting candidates to be hired or promoted in expectation of them entering parenthood (Correll, Benard, and Paik 2007; Acker 2012). Employers may prefer men if they expect women to leave the labor market or reduce their attachment to the firm after entering motherhood. However, employers may also choose to support to-be-fathers as male-breadwinners that should secure the economic wellbeing of the household.

This previous example demonstrates how the interplay between labor market resources, family demographic processes, and discrimination can translate into gender and race differences in pathways out of in-work poverty (Van Winkle and Fasang 2020). Moreover, these processes generate produce complex advantages and disadvantages between intersectional gender by race groups (Browne and Misra 2003). For example, on the labor market Black and Hispanic individuals tend to be concentrated in low wage and low skill occupations, while white employees tend to find themselves in high wage and high skill 
occupations (Willson 2003; Charles and Grusky 2004; Aisenbrey, Evertsson, and Grunow 2009). However, minority women are more likely to find themselves employed in poorly paid, insecure domestic service occupations, while white women are able to attain more prestigious occupations (Browne and Misra 2003). Thus among women, white women may find it easier to escape in-work poverty quickly by earning more, while minority women may find in-work poverty a more persistent state and exit it only through temporary unemployment or only moderate increases in income.

These processes are intensified by differences in norms and practices surrounding gender and the household division of labor between gender and race groups. For example, motherhood and employment are not seen to be mutually exclusive in Black households (Willson 2003). A historical resistance to institutionalized household inequalities and childcare provision through extended kin networks result in dual-earner households being more common among Black compared to Hispanic and white households (Glauber 2007). However, higher rates of single mother and thus single female-breadwinner households are also more common among Black compared to Hispanic and white households. Black women may be less able to rely their partners for income security, in part due to higher household instability but also because Black fathers tend to profit less from fatherhood wage premiums in terms of income and employment (Parrott 2014). One reason may be that employers view Black fathers as less reliable male-breadwinners than their Hispanic and especially white counterparts (Glauber 2008). In contrast, female-homemaker traditions are stronger among white, and to a lesser extent among Hispanic households. Higher marriage rates among Hispanic and white men and women not only signal the intention to enter parenthood, but secure state and federal income benefits linked to marriage. Therefore, pathways out of in-work poverty through an increase income by other household members may be more likely among high income male- 
breadwinner Hispanic and white households than low income dual-earner or single femalebreadwinner Black households.

In sum, we expect pathways out of in-work poverty to be stratified by gender and race due to differences in labor market resources and family demographic behavior, differential selection into employment and poverty, and discrimination on the labor market. Disadvantageous pathways out of in-work poverty will likely be characterized by volatile transitions comprised of an impoverished exit out the labor market, remaining at-risk of poverty and social exclusion, and returns to in-work poverty. In contrast, more advantageous pathways out of inwork poverty will likely be characterized by durable transitions out of poverty. Specifically, we hypothesize that men will experience more advantageous pathways out of in-work poverty than women (H1) and that white individuals will experience more advantageous pathways out of in-work poverty than Black and Hispanic individuals (H2). In addition, we hypothesize that there are intersectional gender by race differences in the likelihood to experience more advantageous pathways out of in-work poverty (H3).

\section{DATA AND METHODS}

\section{Sample}

We use the Panel Study of Income Dynamics (PSID) to empirically assess our research questions and hypotheses. The PSID is a nationally representative household panel, which sampled approximately 18,000 individuals within 5,000 households in 1968. PSID continues to collect economic, sociological and demographic information annually. Since 1997, however, the PSID is collected on a biennial basis. ${ }^{2}$

\footnotetext{
${ }^{2}$ The collection of PSID was partly supported by the National Institutes of Health under grant number R01 HD069609 and R01 AG040213, and the National Science Foundation under award numbers SES 1157698 and
} 


\section{Individual Employment and Poverty Trajectories}

In line with the vast majority of the in-work poverty literature (see Lohmann and Marx [2018] and Polizzi et al. [2020] for a review), individual respondents are out unit of analyses and their poverty status is based on the level of resources available within the household. We therefore constructed trajectories for respondents as sequences using annual information on individual labor market attachment, household income, and household size. ${ }^{3}$ We restricted the observational window between ages 18 and 50 to ensure that non-working statuses do not encompass (early) retirement. To define sequence states, we cross-tabulated labor market status with the poverty status of the respondent's household (see Figure 1). We considered respondents to be employed if they worked over 20 hours a week averaged over the previous year. This corresponds with working full-time for at least 26 weeks or working part-time for a full year. Respondents that worked under 20 hours a week averaged over the past year were defined as not working. PSID provides information on the average number of hours worked per year, which is constructed by questions on number of weeks worked in the previous year and average number of hours worked per week in the previous year. Please note that weeks in military service will be reported as employment, maternity leave would not be counted toward weeks of employment.

Working individuals with gross household incomes under the absolute poverty threshold were defined as "working, absolute poverty", and those not working as "not working, absolute poverty". We used the official US Census Bureau poverty thresholds to define our absolute poverty thresholds. Note that these threshold is set at three times the cost of a

1623684. We use an amended version of the WZB-PSID code for data preparation generated by David Brady and Ulrich Kohler.

3 All sequence analysis steps were performed by using the $\mathrm{R}$ packages TraMineR and TraMineRextras (Gabadinho et al. 2011), version R. 4.0.2. (R Core Team 2020). 
minimum food diet in 1963 adjusted for family size and inflation. We use the US Census Bureau poverty thresholds for two reasons. First, they have a real meaning in the US context in terms of access to welfare programs. Second, they are extremely conservative in that they limit the number of individuals in our in-work poverty group. The absolute poverty threshold calculated by US Census Bureau is systematically lower than the relative poverty measure commonly used by Eurostat. For example, in 1997 the relative poverty threshold for net equivalized household incomes was roughly 18,100 USD compared to gross household incomes of 8,100 USD for single households and 10,500 USD for households with two persons (see in-work poverty trends by gender and race in the US based on relative and absolute thresholds in Figure A1 in the Appendix).

The relative poverty threshold was defined as 60 percent of the median net equivalized household income. ${ }^{4}$ Therefore, individuals were "working, relative poverty" if they were employed for at least an average of 20 hours in the previous year and have household incomes under the relative poverty threshold. ${ }^{5}$ Respondents that are working, but have household incomes over the relative poverty threshold were characterized as "working, not poor". Respondents that are not working and live in households under the relative poverty threshold were categorized as "not working, relative poverty". Incorporating both the relative and absolute poverty thresholds when defining our sequence states allowed us to identify the cross-sections of poverty and employment status conceptualized in Figure 1. The states

\footnotetext{
${ }^{4}$ Because the relative poverty threshold might change every year as a result of changes in the overall income distribution, in a few cases the transition out of (in-work) poverty may be an artifact of the shift of the poverty threshold, especially when the household income is very close to it. Notice, however, that changes in the income distribution of a size that can significantly affect the poverty threshold only occur as a consequence of macrolevel events such as sudden economic downturns or rapid economic growth. We could not adjust the absolute poverty threshold, but we re-run all analyses by setting the relative poverty threshold $70 \%$ to consider whether we are overestimating the transitions out of in-work poverty when using a more conservative threshold $(60 \%)$. Results (available upon request) do not substantively different from those presented here in terms of both pathways identified and estimates.

${ }^{5}$ A general agreement exists on the fact that the unit of analysis for income (after taxes) has to be the household (Filandri and Struffolino 2018; Lohmann and Marx 2018; Thiede, Lichter, and Sanders 2015). EUROSTAT considers workers those who were employed for at least 7 months (approximately 28 weeks) and uses 50-66\% of the median as threshold for being at risk of poverty, but these choices are subject of a lively debate (Atkinson et al. 2002; Crettaz 2013).
} 
"working, not poor" and "not working, not poor" indicate the condition of having a household income above the relative poverty threshold and being employed or nonemployed, respectively. In this last case, social inclusion is guaranteed by the household resources only.

The maximum sequence length is 27 years. Our combined sample consists of 21,177 sequences (see Table A1 in the Appendix for descriptive statistics on the study samples). In addition, we only use information that was collected while the PSID was fielded annually, which means our study analyzes pathways out of in-work poverty from 1970 to 1997 . We conducted several sensitivity analyses to gain an understanding of whether our analyses based on older annual data are still insightful for more recent periods (see Supplement C: Robustness Checks). For example, we conducted analyses on all available PSID data, including the biennial information from 1999 to 2015 as well as the 1979 and 1997 National Longitudinal Studies of Youth up until the mid-2000s. These analyses indicate that our more conservative analyses with annual information still speak to contemporary gender and race differences in pathways out of in-work poverty in the $21^{\text {st }}$ century as well.

\section{Methods}

For our research question, event history analysis (EHA) and sequence analysis (SA) by themselves were insufficient, because our aim was to estimate how time-varying factors affect the probability of following a specific pathway after the end of an episode in in-work poverty. EHA and SA are commonly portrayed as stemming from two different traditions of life course research (Billari 2005). EHA is concerned with if and when a transition occurs, such as the probability and timing of first birth, and the relationship between time-varying covariates and observed durations (Box-Steffensmeier and Jones 2004). SA is interested in 
trajectories that consist of a longitudinal series of categorical states, such as employment life courses (Silke Aisenbrey and Fasang 2010). One aim of SA has been to identify patterns of sequential equivalence.

We therefore used sequence analysis multistate models (SAMM), a stepwise procedure that allows the study of the relationship between time-varying covariates and the hazard of following distinct trajectories of categorical states following a given transition (Studer et al. 2018). SAMM enabled us to 1) empirically identify pathways out of in-work poverty, 2) estimate the associations between gender and race with each pathway out of in-work poverty, and 3) estimate the extent that these associations are attenuated by labor market related characteristics and family demographic behavior. The SAMM consisted of five steps, which we present in detail below applied to our study.

\section{Step I: Extracting Subsequences Out for In-Work Poverty from Individual Sequences}

A subsequence is a sequence of consecutive states of a given length that begins with a given transition and is at least one state shorter than the original sequence. Subsequences enable researchers to isolate trajectories that immediately follow a given transition. Our subsequences began with a transition out of the state "working and poor" and are five years long. Therefore, each sub-sequence we extracted begins with the state "working and poor" followed by the next four states in the original sequence. 

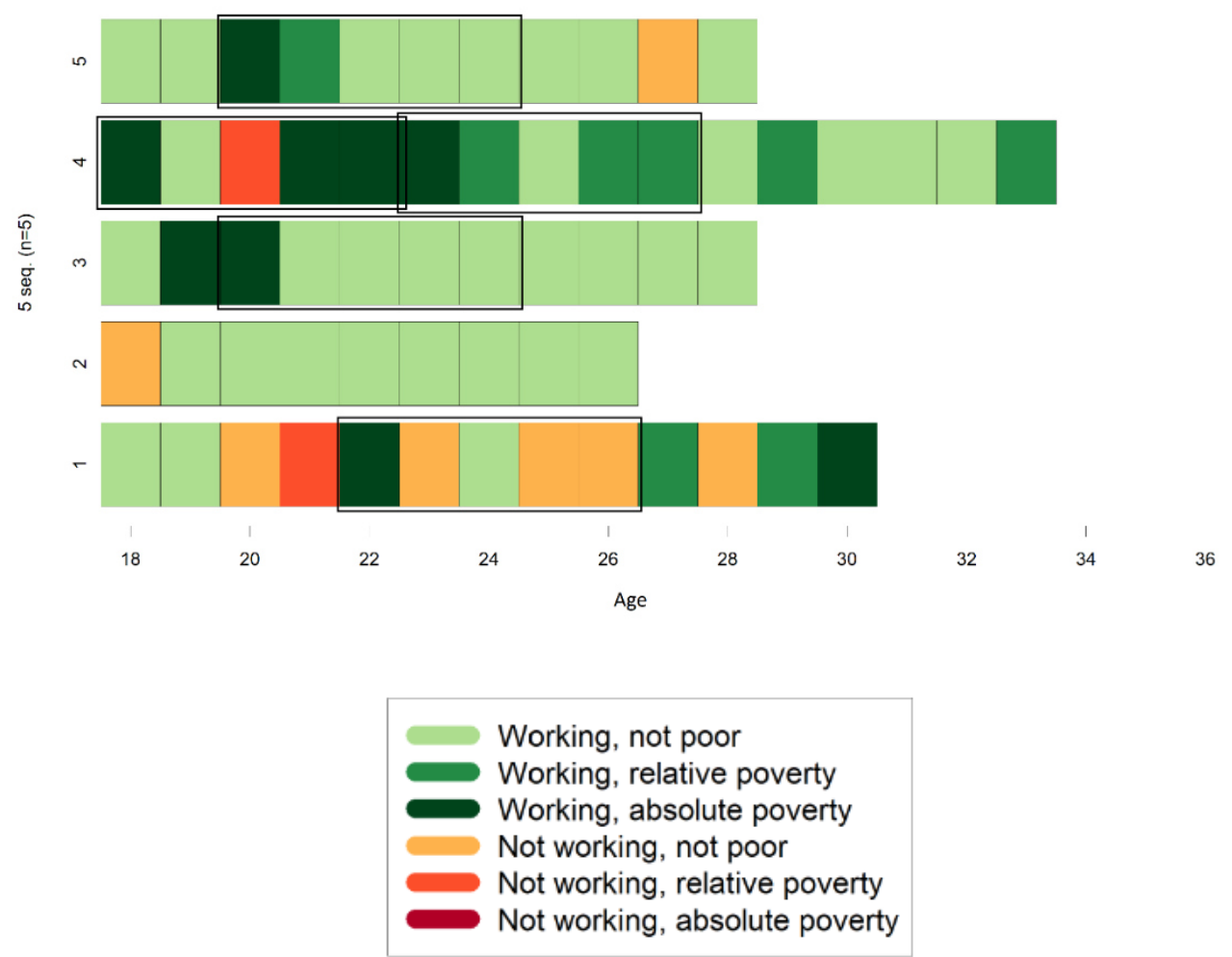

An example of the extraction of five subsequences beginning with a transition out of in-work poverty from four sequences of varying lengths is displayed in Figure 2. The third sequence consists of one year "working and not poor" at age 18, followed by two years "working and poor", and ending at age 28 after 8 years of "working and not poor". We extracted one subsequence from this sequence starting from time point 3 , "working and poor", followed by the next four time points, "working and not poor". Similarly, we extracted one subsequence from sequence 1 and 5 . In sequence 5, the extracted subsequence also begins with "working and poor", but is followed by one year "working and at-risk" and then three years "working and not poor". The subsequence extracted from sequence 1 includes one year of "not working and not poor", followed by one year "working and not poor" and two years "not working and not poor". Note that the last state observed in sequence 1 is "working and poor". However, this cannot be the beginning of a sub-sequence as we do not observe a transition out of in- 
work poverty or four additional years of observation. We extracted two subsequences from sequence 4 , because we observe two transitions out of in-work poverty. The first subsequence begins at age 18 and ends with two years of in-work poverty at ages 21 and 22. The second subsequence starts at age 23 with a second transition out of in-work poverty. Therefore, individual sequences can provide multiple subsequences that may even overlap with one another. Note that we cannot extract any subsequences from sequence 2 , as in-work poverty is never experienced. Therefore, this individual will not contribute to the analyses discussed further below.

We observed 2,812 individuals that contribute 3,964 subsequences that begin with a transition out of the state "working and poor", and 6,348 spells of in-work poverty. After listwise deletion on missing on the independent variables progressively included in the models (see below), our sample dropped to 2,630 individuals, 3,645 subsequences, and 6,033 spells.

Step II: Calculating Dissimilarities between Subsequences.

The subsequences extracted in step I above were then aligned, as displayed in Figure 3, so that all subsequences begin with the state "working and poor" at time 1 . The following states were then located at time $2,3,4$, and 5 . 


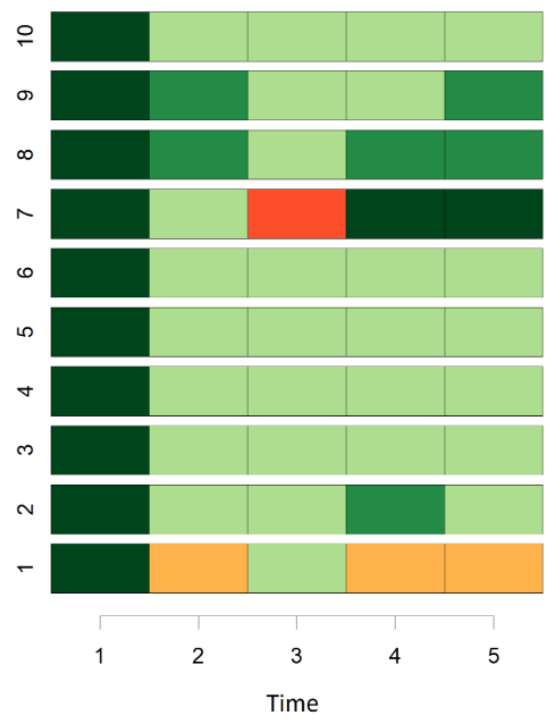

Working, not poor

Working, relative poverty

Working, absolute poverty Not working, not poor

Not working, relative poverty

Not working, absolute poverty

We then calculated a pairwise distance matrix between subsequences using the longest common substring (LCS) distance measure (Elzinga 2014). ${ }^{6}$ Substrings are elements that can be extracted from the entire sequences considered: these elements are defined as tokens and can be either the single states of the alphabet or a combination of subsequent states that occur next to each other along the sequences (Raab and Struffolino forthcoming). LCS is calculated as the sum of the sequence lengths minus twice the length of the longest common substring:

$$
\operatorname{diss}_{L C S}=A(\operatorname{seq} 1, \operatorname{seq} 1)+A(\operatorname{seq} 2, \text { seq } 2)-2 A(\operatorname{seq} 1, \text { seq } 2)
$$

6 LCS normally stands for the longest common subsequence: we use the term substring to avoid confusion with the term "subsequence" in the application of SAMM below in this section. LCS is a non-alignment technique. Nonalignment techniques also include techniques based on the computation of dissimilarities between state distributions. These techniques compare sequences with respect to the time spent in each state. The dissimilarity between sequences is measured by the distance between the vectors of time spent in each state using either the Euclidean distance or the Chi-square distance. For details about these less commonly used dissimilarity measures, see Studer and Ritschard (2016). 
We chose LCS over other sequence distance measures, such as dynamic hamming distance or optimal matching with substitution costs, because it emphasizes order as opposed to timing in sequences (Studer and Ritschard 2016). This is important, because our subsequences were relatively short and there was relatively little variance in the timing of events across subsequences.

\section{Step III: Clustering Subsequences.}

We applied the partitioning around medoids (PAM) clustering algorithm to the LCS dissimilarity matrix, which separates an initial set of sequences in subgroups characterized by the highest possible within-group homogeneity and between-group heterogeneity (Studer 2013). ${ }^{7}$ Medoids are observed sequences that have the smallest sum of dissimilarities to the other sequences of the cluster they belong to. We chose a five cluster solution based on both the average width silhouette (AWS) values and substantive considerations. ASW indicates the coherence of a cluster solution. High ASW values signal that distances between the sequences of different clusters are large, while distances between the sequences within each cluster are small. We opted for a five-cluster partition, because it had a high ASW value and

\footnotetext{
${ }^{7}$ The PAM algorithm is based on an iterative process. The process is initiate with setting the wanted number $\mathrm{k}$ of groups, and (arbitrarily) select k cases as reference case for each cluster. This reference "case" is the medoid, which is calculated as the mean dissimilarity between all cases assigned to the cluster so that it does not have to correspond to a case in the cluster, while the medoid is a case taken as representative of the cluster as it is the most central observed case that minimizes the sum of distances to all other cases. Regardless the reference case, the process starts with the random assignment of cases to the $\mathrm{k}$ groups initially set. The reference case is then reidentified for each group and then each case is re-assigned to the group to whose reference case is the closest. The reference case of these new clusters are newly determined and the process of assignment and identification of the reference cases is iterated until the is no change in the allocation to the clusters. Compared to hierarchical clustering, partitional clustering presents the advantage of maximizing a global criterion rather than a local criterion and allows for faster computation because of the comparison to the reference cases only rather than between all cases (Raab and Struffolino forthcoming).
} 
substantively allowed us to isolate clusters that were not simply characterized by one single state but rather by more pronounced dynamics between states. ${ }^{8}$

Step IV: Mixed Effects Competing Risks Cox Hazard Regressions.

We used the clusters as the dependent variables in mixed effects Cox proportional hazard regressions with competing risks to estimate gender and race differences in the likelihood of experiencing these pathways and to account for these differences (for an example of the data structure see Figure A4 in the Appendix). Cox proportional hazard regressions evaluate the association between covariates and the ratio between the hazard rate and the hazard of a baseline model by assuming that this ratio remains proportional (Box-Steffensmeier and Jones 2004, 47-68). In our case, process time began when an individual enters in-work poverty and ended upon that individual's exit out of in-work poverty or until the individual was no longer observed, i.e. right censored. To reduce the problem of left censoring, we excluded in-work poverty spells when the first observation was in the state "working and poor". The hazard rate of exiting in-work poverty into any other state $\lambda$, at time $t$, for a given individual $\mathrm{j}$, was modelled as:

$\lambda_{j}(t)=\lambda_{0}(t) e^{X_{j} \beta}$

where the covariates and regression parameters $X_{j} \beta$, are multiplicatively related to the baseline hazard function $\lambda_{0}$, of exiting in-work poverty into any other state. For our purposes, we needed to extend this model to account for multiple failure types and failures per subject.

\footnotetext{
${ }^{8}$ If certain age, period, or cohort groups are over-represented in one or more of the clusters, then our results would not be generalizable to the working-age population across our study timeframe. The percentage of our clusters by age, by period, and by birth cohort are displayed in Figure A3 in Appendix. Altogether, the distributions are quite stable across age, periods, and birth cohort, which indicates that a single group does not drive our results.
} 
To accomplish this, we estimated a number of mixed effects Cox models with competing risks (Ripatti and Palmgren 2000; Therneau, Grambsch, and Pankratz 2003). Here the hazard rate $\lambda$, at time $t$, of a failure type $k$, for the $i^{\text {th }}$ failure or censor of an individual $j$, was modelled as:

$\lambda_{i j, k}(t)=\lambda_{0 k}(t) e^{X_{i j} \beta+b_{j}}$ $2 \mathrm{a}$

where the covariates and regression parameters $X_{\mathrm{ij}} \beta$, are multiplicatively related to the baseline hazard function specific to the failure type $\lambda_{0 \mathrm{k}}$. In this case, process time began when an individual enters in-work poverty and ended when an individual exits in-work poverty through the failure type, i.e. cluster, or was censored. The estimated standard errors were corrected for multiple failures and censored spells from individuals by incorporating individual random intercepts $b_{j}$, into the regression models:

$b_{j} \sim N\left(0, \sigma^{2}\right)$

As is the case in applications with linear mixed random effects models, the variance of our random intercepts was assumed to be normally distributed with a mean of zero and a variance of $\sigma^{2}$, as displayed in equation $2 b$.

We estimated six models to test our hypotheses. We first assess whether there are intersectional differences between in pathways out of in-work poverty or whether separate gender and race indicators are sufficient (H3). To this end, we first estimate estimated gender and race differences in the hazard ratio of exiting in-work poverty through each pathway we identified in a baseline Model 0. We then estimate our Model 1 that includes an interacted gender by race indicator and compare the two models using likelihood ratio tests. If the fit of Model 1 is statistically better than the baseline Model 0 , then we have strong evidence that there are intersectional differences. These models also allow us to describe unadjusted gender and race differences in our pathways out of in-work poverty $(\mathrm{H} 1$ and $\mathrm{H} 2)$. 
In our following models we include time-varying covariates that act as mediators, which hint as to test whether the mechanisms we outlined above are plausible drivers of the gender and race differences we observe. We then move to Model 2 includes an inverse Mill's ratio for selection into in-work poverty. We follow a two-step Heckman selection correction approach adapted for longitudinal data. Specifically, we estimate the probability that a respondent in a given year belongs to the working poor or not using random effect probit models. We incorporate a number of covariates including the average number of weekly hours worked over the past year, respondents' marital status, family size, birth year, and age. All further models include this selection indicator.

Model 3 included indicators for educational attainment, work experience, and occupational group (that is labor market indicator variables). Educational attainment referred to years of education corresponding with the highest grade completed at the time of the interview. Work experience reflected the current cumulative number of years employed since age 18 . We used a revised version of the one-digit ISCO scheme to group current occupation into i) management and professionals, ii) technical, sales, and administrative support, iii) service, iv) farming, fishing, craft, and production, v) operators, fabricators, and laborers, and vi) military service or out of the labor force. Model 4 included three family demographic indicator variables measured at the time of the interview: 1) whether the respondent lives in the parental home, 2) whether the respondent is childless, has one child, two children, or three or more children, and 3) whether the respondent has never been married, is married, or is separated or divorced. Finally, Model 5 included both labor market and family demographic indicator variables at once.

All models include respondents' year of birth, age, and age-squared. Note that all covariates that varied across time (e.g. educational attainment, number of hours worked, or the number of children relative to each year) were entered into the models as time-varying covariates. 
This means that for each subsequence the value of these covariates was measured at the year when the transition out of in-work poverty occurred. If another subsequence out of in-work poverty is extracted for the very same individual the value of the covariate is aligned to the time point corresponding to the starting point of this subsequence.

The race variable distinguished between white, Black, and Hispanic individuals. We excluded Native Americans, Asian Americans, and Pacific Islanders to ensure that the white category comprised only individuals of European or Western descent or ancestry. This is important so that our categories did not combine groups that are not equally privileged or marginalized. We included gender and race as a single categorical variable in all models, i.e. white men, white women, black men, etc., to account for intersectionalities between gender and race. Several robustness checks ensured that our results were not driven by differences in the sample size across models, by the inclusion of weighting schemes, the length of subsequences, and the dataset used (see the Supplement C). ${ }^{9}$

\section{RESULTS}

Cluster Analysis Results: Pathways Out of In-Work Poverty

What pathways did individuals follow transitioning out of in-work poverty? Figure 4 displays the results of the cluster analysis. Each plot depicts 100 subsequences that represent their cluster. By construction, every subsequence begins in the state "working and poor". We extracted five clusters: 1) immediate recovery, 2) turbulent recovery, 3) continuous

\footnotetext{
${ }^{9}$ To highlight the added value of our analytical strategy, we estimated Cox regressions on the hazard rate of exiting in-work poverty (see Supplement A). Nearly all individuals, regardless of gender or race, exited in-work poverty after six years. However, the gender and race differences in the hazard of exiting in-work poverty cannot indicate of what happens to individuals in the years following their exit out of in-work poverty. As a matter of fact, these results can only convey information on whether in-work poverty represents a shorter or longer phase in individuals' lives and whether there are differences by gender and race.
} 
vulnerability, 4) cyclical in-work poverty, and 5) impoverished non-employment. An overview of composition of the clusters can be found in Table A2 in the Appendix.

Figure 4: Relative Frequency Sequence Plots of Pathways Out of In-Work Poverty Clusters

1. Immediate recovery $(24.5 \%)$

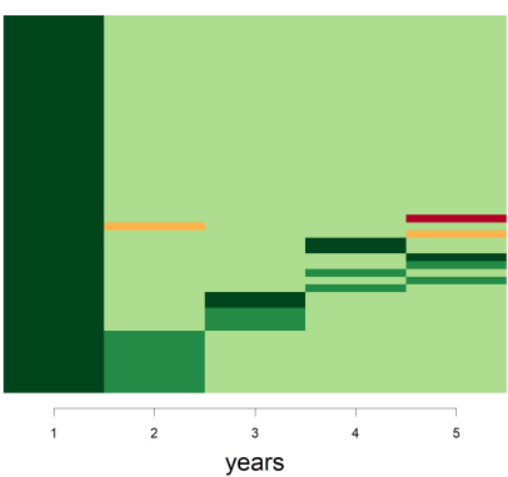

3. Continuous vulnerability (25.1\%)

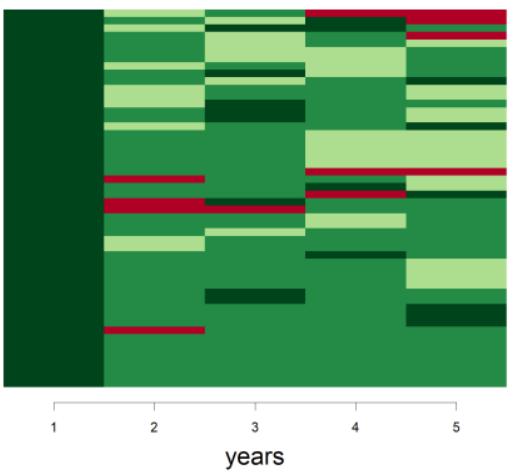

5. Impoverished non-employment $(15.8 \%)$

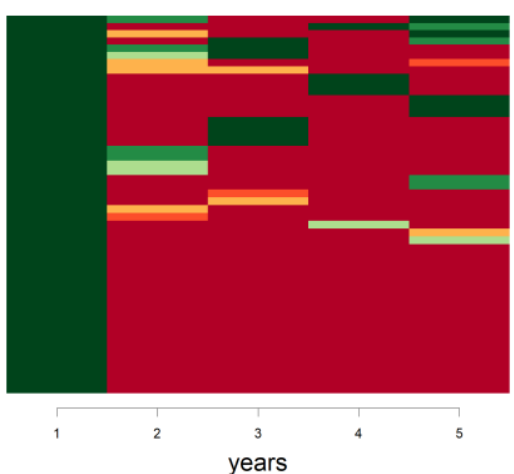

2. Turbulent recovery $(21.2 \%)$

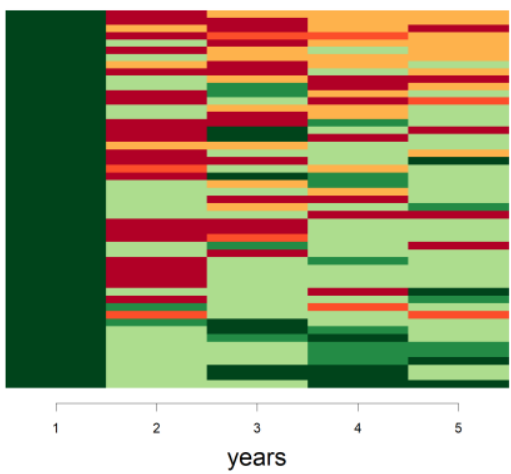

4. Cyclical in-work poverty (13.4\%)

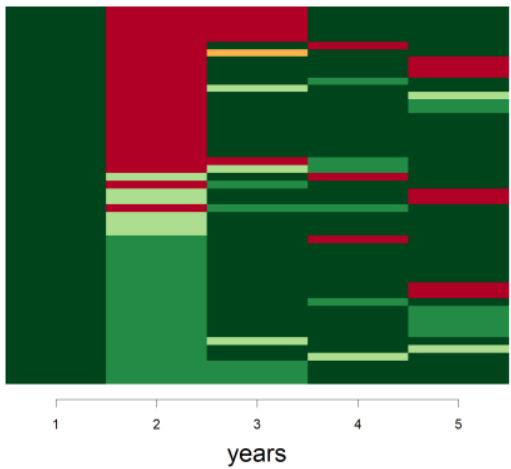

years

Working, not poor

Working, relative poverty

Working, absolute poverty

Not working, not poor

Not working, relative poverty

Not working, absolute poverty

Source: PSID. The relative frequency sequence plots are produced using the seqplot.rf R function (Fasang and Liao 2014). Sequences in each cluster are ordered according to their complexity and then partitioned into 50 frequency groups. For each frequency group, the medoid sequence is selected as representative on the basis of the dissimilarity matrix computed as input for the cluster analysis. The selected representatives are plotted as sequence index plots. Sequences are ordered according to the multidimensional scaling criterion. The dissimilarities to the medoids within each frequency group and the goodness of fit are displayed in Figure A2 in the Appendix. 
The cluster "immediate recovery" ( 24.5 percent of all subsequences) was characterized by a direct exit out of in-work poverty into stable employment outside of poverty. Compared to all other clusters, this was the most advantageous pathway out of in-work poverty, which seems to guarantee long-lasting social inclusion linked to both employment and household resources. Individuals in our cluster "turbulent recovery" (21.2 percent of all subsequences) tended to escape absolute poverty either employed or not employed. However, individuals in this cluster experienced an instable transition out of in-work poverty characterized by alternate years in and out of employment. In most cases, the years out of employment are accompanied by absolute poverty. Although most individuals are not poor after five years from exiting in-work poverty, for some this is guaranteed by household resources rather than by their own employment. Approximately 25.1 percent of transitions out of in-work poverty were characterized by "continuous vulnerability". While these individuals remained employed and exited absolute poverty, they remain at a constant risk of in-work poverty.

Two clusters, "cyclical in-work poverty" and "impoverished non-employment", represented extremely turbulent and volatile pathways: the former indicates a regression to (long-lasting) in-work poverty, the latter leads to mid-term social exclusion .More specifically, upwards of 13 percent of all subsequences were characterized by a regression back into in-work poverty within four years. Many of these individuals escaped in-work poverty by exiting the labor market or slipping out of absolute poverty. The last cluster ("impoverished nonemployment", 15.8 percent of all subsequences) demonstrated either persistency in at-risk of poverty or in absolute poverty outside of the labor market. As we expected, there was no single pathway out of in-work poverty, but rather a number of pathways characterized by different degrees of economic vulnerability, labor market attachment, and volatility. 
Were there gender and race differences in pathways out of in-work poverty? The results of the competing risk Cox models for the hazard rate of leaving in-work poverty through one of the five pathways types we identified are displayed in Table B1 in the Supplement B. Overall, our hypothesis 1-that men would experience more advantageous pathways out of inwork poverty than women-and our hypothesis 2-that white individuals would experience more advantageous pathways out of in-work poverty than Black and Hispanic individualswere supported by our results. Compared to men, women were less likely to exit in-work poverty through the "immediate recovery" pathway. Similarly, Black but not Hispanic men and women are less likely than white individuals to leave in-work poverty through the "immediate recovery" pathway. For example, the change in the log hazard ratio for Black individuals of "immediate recovery" compared to remaining in in-work poverty or exiting using another pathway was 0.75 lower than white individuals. Women had a higher propensity than men of exiting in-work poverty into the "turbulent recovery" cluster, while this was lower for Black individuals compared to white individuals. Compared to men and white individuals, women and minority individuals, respectively, had a lower propensity to leave the working poor into a trajectory of "continuous vulnerability". Black individuals were more likely than white individuals to only temporarily exit in-work poverty into a pattern of "cyclical in-work poverty", with no differences between men and women and between Hispanic and white individuals. Finally, women and Black individuals had a higher propensity to leave into a trajectory of "impoverished non-employment" when compared to men and white individuals, respectively.

However, are there intersectional differences as postulated by out third hypothesis? We used likelihood ratio tests (see Table 1) to estimate whether models including an interacted race model (Model 1, with basic controls, Table B2 in the Supplement B) is statistically better than a model including gender and race as separate variables (Model 0, with basic controls, 
Table B1 in Supplement B). For four of our five clusters, we find that our models are not statistically improved by including an interacted gender by race variable $(p>0.05)$. We only find a considerable model improvement for our "turbulent recovery" cluster when we consider gender by race differences $(p<0.001)$. Therefore, we find little evidence in support for our third hypothesis on intersectional differences in pathways out of in-work poverty.

Table 1: Likelihood ratio tests for models including gender and race as separate variables compared to models including gender and race as an interacted variable

\begin{tabular}{rccccccc}
\hline & Model 0 & & Model 1 & \multicolumn{3}{c}{ Likelihood Ratio Tests } \\
Cluster & Log Likelihood & df & Log Likelihood & df & $X$ & df & $p\left(X^{2}>X\right)$ \\
\hline 1 & -6750.05 & 8 & -6750.55 & 10 & 1.00 & 2 & 0.6053 \\
2 & -5984.10 & 8 & -5993.05 & 10 & 17.89 & 2 & 0.0001 \\
3 & -6778.22 & 8 & -6777.90 & 10 & -0.64 & 2 & 1.0000 \\
4 & -3778.00 & 8 & -3779.48 & 10 & 2.95 & 2 & 0.2288 \\
5 & -4244.45 & 8 & -4244.93 & 10 & 0.95 & 2 & 0.6219 \\
\hline
\end{tabular}

Note: Likelihood ratio $(X)$ calculated as $-2\left(L L_{1}-L L_{0}\right)$ and is assumed to be $X^{2}$ distributed with $\mathrm{df}_{1}-\mathrm{df}_{0}$ degrees of freedom. All models are adjusted for number of earners in the household, birth year, age, time. Source: PSID. Full tables in the Supplement B, Table B1(model 0) and B2 (model 1).

Figure 5 displays the gender by race coefficients and their 95 percent confidence intervals with white men as the reference category across Models 1 to 5 . The name of the cluster, i.e. the failure type of the given model, is shown on the left side of Figure 5. The coefficients denote changes in the log hazard rate of transitioning out of in-work poverty through a given pathway compared to leaving through the other pathways or remaining in in-work poverty. Positive values indicate faster and more likely transitions, while negative values indicate slower and less likely transitions. In the Supplement B, Table B2 reports the full table and the results of models using the other gender-race categories as references can be seen in Figures B1-B5.

Model 1 (black markers in Figure 5) shows that compared to white men, Black men, Black women and White women were less likely to exit in-work poverty through the "immediate recovery" pathway. For example, the change in the log hazard ratio for Black women of 
"immediate recovery" compared to remaining in in-work poverty or exiting using another pathway was 1.1 lower than white men, but only 0.3 lower for white women. White and Hispanic women had a higher propensity than white men of exiting in-work poverty into the "turbulent recovery" cluster. This second cluster is the only one where we found statistical evidence for intersectional differences. Indeed, non-interacted gender and race indicators would not demonstrate that Hispanic women - as opposed to Black women and Hispanic men - have a higher propensity than White men to escape in-work poverty through the "turbulent recovery" cluster relative to other clusters or remaining in in-work poverty.

Another key finding is that Black men and women as well as Hispanic and white women had a lower propensity than white men to leave the working poor into a trajectory of "continuous vulnerability". However, Black men and women have considerably higher propensities than whites and Hispanics to only temporarily exit in-work poverty into a pattern of "cyclical inwork poverty". Moreover, Black men and all women had a higher propensity to leave into a trajectory of "impoverished non-employment". Including a term to capture selection into inwork poverty in Model 2 (grey markers), had no substantive influence on our estimates.

Model 3 (blue markers), which included educational attainment, labor market experience, and occupational group, influenced the gender-race associations with the pathways out of in-work poverty only to a small degree. The only point estimate to become statistically different to the baseline model was the lower propensity for Black men to exit in-work poverty into the "immediate recovery" cluster, although the coefficient remained statistically different from zero. No other point estimates between the baseline model and model 3 were statistically different from one another and only a limited number of estimates were no longer statistically different from zero. For example, white women were no longer statistically less likely to leave in-work poverty through the "immediate recovery" pathway compared to white men, 
and Black men were no longer statistically more likely to leave through the "impoverished non-employment" pathway. 
Figure 5: Competing risk Cox model for the probability of leaving in-work poverty through one of the five pathways (ref. White men)

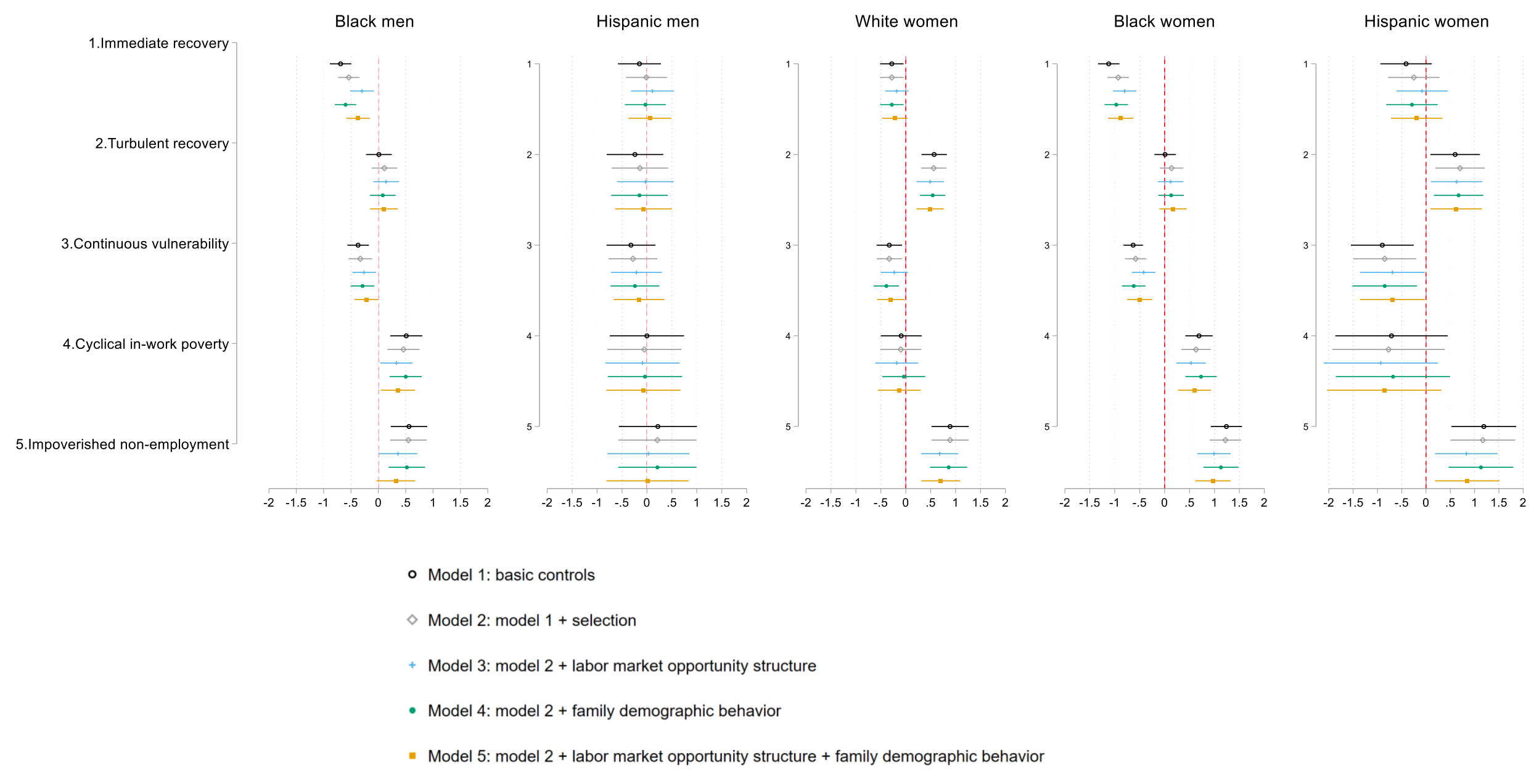

Note: Unstandardized coefficients and 95\% confidence intervals; All models are adjusted for number of earners in the household, birth year, age, time. Source: PSID. 
Similarly, leaving the parental home, the number of children, and marital status as in model 4 (green markers) changed the relationship between gender-race categories and pathways out of in-work poverty to a small degree. Again, no gender and race point estimates were statistically different from the baseline model and none became statistically insignificant. In sum, the overall results show that no compositional differences in labor market related resources or in family demographic behavior accounted for heterogeneous prevalence of specific pathways out of in-work poverty by the intersection of gender and race pathway. In most cases including labor market and family demographic characteristics in Model 5 (orange markers) had no substantive impact on our estimates.

The estimated associates between our mediators and the pathways out of in-work poverty were in most cases as expected, but not in all cases. For example, higher educational attainment was associated with a higher propensity to exit in-work poverty through the "immediate recovery" pathway, but also through the "turbulent recovery" and "continuous vulnerability" pathways. Educational attainment, as would be expected, was related with a lower propensity for exiting through "impoverished non-employment". We found that compared to being in the military or out of the labor force, occupations requiring a higher skill level, e.g. management and professionals compared to operators and laborers, had higher propensities to leave in-work poverty through more advantageous pathways, such as "immediate recovery" and had considerably lower propensities to exit through disadvantageous pathways, such as "impoverished non-employment". We found that labor market experience had no or only a negligible association with pathways out of in-work poverty. We found very few statistically significant associations between the number of children in the household and our pathways. Any children in the household was related with lower propensities to exit in-work poverty through the "turbulent recovery" pathway. One 
child in the household compared to none was associated with a higher propensity to exit into “continuous vulnerability". We found no statistically significant associations between marital status and our pathways, but respondents living outside the parental home had lower propensities to leave in-work poverty through the "immediate recovery" and "turbulent recovery" pathways but were less likely to remain in "continuous vulnerability".

\section{DISCUSSION}

In-work poverty is of increasing concern in the US and in Europe and it has recently entered the academic and policy prominently. In fact, the existence of impoverished work challenges the idea that promoting employment is the primary (and sufficient step) to lift individuals and their families out of poverty (Lichter and Crowley 2002; Moffitt 2015). Unlike the case of poverty, the temporal dynamics of in-work poverty have not been widely considered in the literature so far. In this paper, we addressed two research questions: what pathways out of inwork poverty exist in the United States and are those pathways out of in-work poverty stratified by gender and race. We hypothesized that pathways out of in-work poverty would encompass varying degrees of labor market attachment, economic vulnerability, and volatility over time and that men and white individuals would experience more advantageous pathways out of in-work poverty than women and Blacks and Hispanic individuals, respectively (H1 and $\mathrm{H} 2$ ). In addition, we hypothesized that there would be intersectional gender by race differences (H3). The results supported our first two hypotheses on gender and race differences. However, contrary to our expectations, we found little support for differences across intersectional groups. Only one of the five pathways out of in-work poverty we identified demonstrated significant within-race gender differences. 
This study makes conceptual, theoretical, and methodological contributions to the fields of social stratification and life course sociology. First, we conceptualized of in-work poverty that goes beyond a binary definition of entering and exiting in-work poverty. We conceptualize in-work poverty in terms of degrees of labor market attachment and household economic hardship that vary over time. This is necessary to reach a thick description of how stratification emerges from the heterogeneity of trajectories that move between social inclusion and exclusion and varying degrees of vulnerability. This conceptualization allowed us to demonstrate that a key longitudinal dimension of inequality has gone unnoticed: pathways out of in-work poverty.

By applying the SAMM procedure to PSID data, we identified a typology of 5-year-long pathways out of in-work poverty and estimate gender and race differences in the likelihood of following each pathway. The five distinct pathways out of in-work poverty that are characterized by varying degrees of labor market attachment, economic vulnerability, social exclusion, and volatility. Striking gender and race differences in pathways out of in-work poverty exist: white men are the most likely to exit in-work poverty into stable employment outside of poverty, while Black men and women are more likely to remain trapped in vulnerable pathways outside of employment and often regress into new spells of in-work poverty. Sizeable differences persisted even after adjusting for labor market related resources and family demographic behavior.

We demonstrate the importance of looking at longitudinal pathways out of in-work poverty by considering how gender and race differences do emerge in line with gender- and racespecific labor market opportunity structures in the US case. Importantly, our results indicate that stratification by gender and race within individuals' life courses after in-work poverty spells have ended cannot be fully accounted for by average differences in labor market characteristics and family demographic behavior. 
A potential explanation for the persistence of such differences might fall under general discrimination mechanisms depending on individuals' social location in the intersection between gender and race. For example, white men will be most likely to receive promotions, lifting them out of in-work poverty. In contrast, Black and Hispanic men and women are more likely to lose their jobs following layoffs. When trying to re-enter the labor market, women may find it more difficult than men, and Blacks and Hispanics may find it more difficult than whites to establish themselves in high paying occupations. Moreover, discrimination by gender and race as well as opportunities for high paying jobs likely varies remarkably across states, because of baseline differences in the integration of minorities in the labor market. Unfortunately, no data sources are available that enable the incorporation of SAMM with detailed geographical data.

Methodologically, the SAMM procedure allowed the identification of heterogeneous pathways out of in-work poverty and of gender and race inequalities that otherwise would be masked by simply modeling the exit from in-work poverty. We believe that SAMM will be useful for a wide range of research areas within and beyond sociology. For example, this procedure can uncover the pathways individuals take after exiting welfare dependency or following participation in active labor market programs. An important question in urban sociology and social stratification research revolves around how the quality of housing change following an eviction and whether the presence of children leads to more trajectories that are amenable. Another relevant area of research in the US is related to how employment and family trajectories develop after incarceration and whether state policies influence those pathways.

The limitations of our study hint where future research and data collection should head to improve our understanding of in-work poverty dynamics. First, the definition of household (equivalized) income and, therefore of the working poor, relies on the debatable assumption 
that wages from work are pooled within households and resources are equally distributed among households' members. Our data do not allow for a formal test of this assumption and therefore household income at each point in time might underestimate the poverty status of specific individuals within households. Unfortunately, this is generally the case when studying poverty. Future data collection and analyses should attempt to incorporate longitudinal data that provide explicit information on within-household redistribution and individual consumption. This issue is related to a limitation of this study: pathways are measured at the individual level relying on own employment status and on household's poverty status. Our approach is consistent with the vast majority of cross-sectional studies in this field. However, our longitudinal perspective implies that changes over time and between the states we identify can be driven by changes in labor market participation and or income of the respondent, another household member or by changes in household composition. For example, the relative probability of exiting in-work poverty via increased economic wellbeing for women, and especially mothers, may be partially driven by changes that occur at the household level. Future research using a longitudinal approach to analyzing pathways out of in-work poverty should attempt build on our conceptual framework and reconcile the individual and household levels of analysis.

Finally, we were unable to account for the unique economic and social contexts for our study samples. While we adjust for differences between birth cohorts and the studies, we are unable to analyze whether the associations between gender and race groups and pathways out of inwork poverty vary across birth cohort due to sample size limitations. However, the respondents in our sample experienced the major recessions of the 1970s and their long-term consequences at different age and thus different career stages. Further, our respondents experienced different degrees of welfare generosity, especially as in 1993 the Earned Income Tax Credit (EITC) was expanded becoming the largest means-tested anti-poverty. However, 
the results we presented have only a limited ability to speak to the effects of the welfare reform in 1996 changed the Aid to Families with Dependent Children (AFSC) to the Temporary Assistance for Needy Families program (TANF). TANF emphasizes the welfareto-work principle. So far it has been found to be associated with anticipated labor market effects, while its effects on improvement in economic wellbeing is less evident (Berger et al. 2018). Therefore, TANF's ability to reduce in-work poverty remains an open question. Further research should concentrate more explicitly on differences across cohorts to better untangle how policy changes affect gender and race differences in pathways out of in-work poverty.

Although we concentrated on the US, future research should also implement a comparative strategy to shed additional light on how macro-level factors affect pathways out of in-work poverty and how they are stratified. The risk factors identified for the US mirror those found in European countries (see Crettaz [2013] for a review). Cross-national differences in the prevalence of in-work poverty have been related to macro-level institutional factors (see Lohmann and Crettaz [2018] for a review), such as labor market regulations (Brady et al. 2010; Crettaz and Bonoli 2011; Filandri and Struffolino 2018) and social policies (Brady et al. 2013; Lohmann and Crettaz 2018). Further, institutions are thought to filter the negative effects that global macroeconomic trends (skill-biased technological change and globalization) have on in-work poverty (Brady et al. 2010; Crettaz 2015). However, we do not know whether the same pathways out of in-work poverty exist in other county-contexts and whether they are socially stratified. 


\section{REFERENCES}

Aassve, Arnstein, Maria A. Davia, Maria Iacovou, and Stefano Mazzuco. 2007. "Does

Leaving Home Make You Poor? Evidence from 13 European Countries.” European Journal of Population/Revue Européenne de Démographie 23 (3-4): 315-38.

Acker, Joan. 2012. "Gendered Organizations and Intersectionality: Problems and

Possibilities." Equality, Diversity and Inclusion 31 (3): 214-24.

https://doi.org/10.1108/02610151211209072.

Aisenbrey, S., M. Evertsson, and D. Grunow. 2009. "Is There a Career Penalty for Mothers'

Time Out? A Comparison of Germany, Sweden and the United States." Social Forces 88 (2): 573-605. https://doi.org/10.1353/sof.0.0252.

Aisenbrey, Silke, and Anette Fasang. 2010. "New Life for Old Ideas: The " "Second Wave" of Sequence Analysis Bringing the "Course"” Back Into the Life Course." Sociological Methods \& Research 38 (3): 420-62.

- 2017. "The Interplay of Work and Family Trajectories over the Life Course:

Germany and the United States in Comparison.” American Journal of Sociology 122 (5): $1448-84$.

Atkinson, Anthony B. 1998. Poverty in Europe. Oxford: Wiley-Blackwell.

Atkinson, Anthony B., Bea Cantillon, Eric Marlier, and Brian Nolan, eds. 2002. Social Indicators: The EU and Social Inclusion. Oxford: Oxford Univ. Press.

Bane, Mary Jo, and David Ellwood. 1986. "Slipping into and out of Poverty: The Dynamics of Spells." Journal of Human Resources 21 (1): 1-23.

Barbieri, Paolo, Giorgio Cutuli, and Stefani Scherer. 2018. "In-Work Poverty in Southern Europe: The Case of Italy.” In Handbook on In-Work Poverty, edited by Henning Lohmann and Ive Marx, 312-27. Cheltenham, UK/Northampton, MA, USA: Edward Elgar Publishing.

Berger, Lawrence M., Maria Cancian, and Katherine Magnuson. 2018. “Anti-Poverty Policy Innovations: New Proposals for Addressing Poverty in the United States." RSF: The Russell Sage Foundation Journal of the Social Sciences 4 (3): 1-19.

Bertrand, Marianne, and Sendhil Mullainathan. 2004. "Are Emily and Greg More Employable Than Lakisha and Jamal? A Field Experiment on Labor Market Discrimination.” THE AMERICAN ECONOMIC REVIEW 94 (4): 97. 
Biewen, Martin. 2009. "Measuring State Dependence in Individual Poverty Histories When There Is Feedback to Employment Status and Household Composition." Journal of Applied Econometrics 24 (7): 1095-1116.

Billari, Francesco C. 2005. "Life Course Analysis: Two (Complementary) Cultures? Some Reflections With Examples From the Analysis of the Transition to Adulthood." Edited by René Levy, Paolo Ghisletta, Jean-Marie Le Goff, Dario Spini, and Eric Widmer. Owards an Interdisciplinary Perspective on the Life Course, 267-88. BLS. 2018. “A Profile of the Working Poor, 2016.” 1074. BLS Reports. U.S. Bureau of Labor Statistics.

Box-Steffensmeier, Janet, and Bradford Jones. 2004. Event History Modeling: A Guide for Social Scientists. Cambridge: Cambridge University Press.

Brady, David. 2018. "Theories of the Causes of Poverty." Annual Review of Sociology 45. Brady, David, Regina S. Baker, and Ryan Finnigan. 2013. "When Unionization Disappears State-Level Unionization and Working Poverty in the United States." American Sociological Review 78 (5): 872-96.

Brady, David, Andrew S. Fullerton, and Jennifer Moren Cross. 2010. "More than Just Nickels and Dimes: A Cross-National Analysis of Working Poverty in Affluent Democracies." Social Problems 57 (4): 559-85.

Browne, Irene, and Joya Misra. 2003a. "The Intersection of Gender and Race in the Labor Market." Annual Review of Sociology 29 (1): 487-513. https://doi.org/10.1146/annurev.soc.29.010202.100016.

_. 2003b. "The Intersection of Gender and Race in the Labor Market." Annual Review of Sociology 29 (1): 487-513. https://doi.org/10.1146/annurev.soc.29.010202.100016.

Bulanda, Jennifer Roebuck, and Susan L. Brown. 2007. "Race-Ethnic Differences in Marital Quality and Divorce." Social Science Research 36 (3): 945-67.

Cappellari, L, and S P Jenkins. 2004. "Modelling Low Income Transitions.” Journal of Applied Econometrics 19 (5): 593-610.

Charles, Maria, and David Grusky. 2004. Occupational Ghettos: The Worldwide Segregation of Women and Men. Stanford, CA: Stanford University Press.

Chudnovskaya, Margarita, and Ridhi Kashyap. 2019. "Is the End of Educational Hypergamy the End of Status Hypergamy? Evidence from Sweden." European Sociological Review, December, jcz065. https://doi.org/10.1093/esr/jcz065. 
Correll, Shelley J., Stephen Benard, and In Paik. 2007. "Getting a Job: Is There a Motherhood Penalty?” American Journal of Sociology 112 (5): 1297-1339. https://doi.org/10.1086/511799.

Crettaz, Eric. 2013. "A State-of-the-Art Review of Working Poverty in Advanced Economies: Theoretical Models, Measurement Issues and Risk Groups.” Journal of European Social Policy 23 (4): 347-62.

Crettaz, Eric, and Giuliano Bonoli. 2011. "Worlds of Working Poverty: National Variations in Mechanisms." In Working Poverty in Europe, 46-69. Springer.

Daly, Mary. 2018. "Towards a Theorization of the Relationship between Poverty and Family." Social Policy \& Administration 52 (3): 565-77.

Daly, Mary C., and Robert G. Valletta. 2006. "Inequality and Poverty in United States: The Effects of Rising Dispersion of Men's Earnings and Changing Family Behaviour." Economica 73 (289): 75-98.

Dewilde, Caroline. 2003. "A Life-Course Perspective on Social Exclusion and Poverty." The British Journal of Sociology 54 (1): 109-28.

Duncan, Greg J., Björn Gustafsson, Richard Hauser, Günther Schmauss, Hans Messinger, Ruud Muffels, Brian Nolan, and Jean-Claude Ray. 1993. "Poverty Dynamics in Eight Countries.” Journal of Population Economics 6 (3): 215-34.

Elzinga, Cees H. 2014. "Distance, Similarity and Sequence Comparison.” In Advances in Sequence Analysis: Theory, Method, Applications, edited by Philippe Blanchard, F. Bühlmann, and Jacques-Antoine Gauthier, 2:51-73. Life Course Research and Social Policies. Springer New York Heidelberg Dordrecht London: Springer International Publishing.

England, Paula, Janet Gornick, and Shafer Fitzgibbons. 2012. "Women s Employment, Education, and the Gender Gap in 17 Countries." Monthly Labour Review 3: 11. Eurostat. 2018. People at Risk of Poverty or Social Exclusion. Eurostat - Statistics Explained. Fasang, Anette E., and Tim F. Liao. 2014. "Visualizing Sequences in the Social Sciences: Relative Frequency Sequence Plots.” Sociological Methods \& Research 43 (4): 64376.

Filandri, Marianna, and Emanuela Struffolino. 2013. "Working Poor: Lavoratori Con Basso Salario o Occupati Che Vivono in Famiglie Povere? Un'analisi Del Fenomeno in Italia Prima e Dopo La Crisi.” Sociologia Del Lavoro 31: 190-205. . 2018. "Individual and Household In-Work Poverty in Europe: Understanding the Role of Labor Market Characteristics.” European Societies 0 (0): 1-28. 
Gabadinho, A., G. Ritschard, N.S. Mueller, and M. Studer. 2011. "Analyzing and Visualizing State Sequences in R with TraMineR.” Journal of Statistical Software 4 (40): 1-37.

Gangl, Markus. 2004. "Welfare States and the Scar Effects of Unemployment: A

Comparative Analysis of the United States and West Germany." American Journal of Sociology 109 (6): 1319-64.

Gießelmann, Marco. 2015. "Differences in the Patterns of In-Work Poverty in Germany and the UK." European Societies 17 (1): 27-46.

Glauber, Rebecca. 2007. "Marriage and the Motherhood Wage Penalty among African Americans, Hispanics, and Whites.” Journal of Marriage and Family 69 (4): 951-61. —. 2008. "Race and Gender in Families and at Work: The Fatherhood Wage Premium." Gender \& Society 22 (1): 8-30. https://doi.org/10.1177/0891243207311593.

Gutiérrez, Rodolfo, Marta Ibáñez, and Aroa Tejero. 2011. "Mobility and Persistence of InWork Poverty.” In Working Poverty in Europe, 175-201. Springer.

Hick, Rod, and Alba Lanau. 2018. "Moving In and Out of In-Work Poverty in the UK: An Analysis of Transitions, Trajectories and Trigger Events.” Journal of Social Policy 47 (4): 661-82. https://doi.org/10.1017/S0047279418000028.

Jarrell, Stephen B, and T D Stanley. 2004. "Declining Bias and Gender Wage Discrimination? A Meta-Regression Analysis.” The Journal of Human Resources 39 (3).

Kenworthy, Lane, and Ive Marx. 2018. "In-Work Poverty in the United States.” In Handbook of In-Work Poverty, edited by Henning Lohmann and Ive Marx, 238-44. Cheltenham, UK/Northampton, MA, USA: Edward Elgar Publishing.

Leisering, Lutz, and Stephan Leibfried. 1999. Time and Poverty in Western Welfare. United Germany in Perspective. New York: Cambridge University Press.

Lichter, Daniel T., and M.L. Crowley. 2002. Poverty in America: Beyond Welfare Reform. Vol. 57. Population Bulletin. Wachington (DC): Population Reference Bureau. Lohmann, Henning, and Eric Crettaz. 2018. "Explaining Cross-Country Differences in inWork Poverty." In Handbook of In-Work Poverty, edited by Henning Lohmann and Ive Marx, 50-69. Cheltenham, UK/Northampton, MA, USA: Edward Elgar Publishing.

Lohmann, Henning, and Ive Marx, eds. 2018. Handbook on In-Work Poverty. Cheltenham, UK: Edward Elgar Publishing.

Moffitt, Robert A. 2015. "The Deserving Poor, the Family, and the U.S. Welfare System." Demography 52 (3): 729-49. 
Negri, Nicola, and Chiara Saraceno. 2000. "Povertà, Disoccupazione Ed Esclusione Sociale.” Stato e Mercato 59 (2): 175-210.

Parrott, H. M. 2014. “Housework, Children, and Women's Wages across Race-Ethnic Groups." Social Science Research 46: 72-84.

Paugam, Serge. 1998. "Poverty and Social Exclusion: A Sociological View." In The Future of European Welfare. A New Social Contract?, by Martin Rhodes and Yves Meny, 63-78. New York: St Martin's Press.

R Core Team. 2020. R: A Language and Environment for Statistical Computing. Vienna, Austria: R Foundation for Statistical Computing. http://www.R-project.org.

Raab, Marcel, and Emanuela Struffolino. forthcoming. Sequence Analysis. Quantitative Applications in the Social Sciences. SAGE.

Reid, Lesley Williams, and Beth A. Rubin. 2003. "Integrating Economic Dualism and Labor Market Segmentation: The Effects of Race, Gender, and Structural Location on Earnings, 1974-2000." Sociological Quarterly 44 (3): 405-32.

Ripatti, Samuli, and Juni Palmgren. 2000. "Estimation of Multivariate Frailty Models Using Penalized Partial Likelihood." Biometrics 56 (4): 1016-22. https://doi.org/10.1111/j.0006-341X.2000.01016.x.

Rowntree, Benjamin Seebohm. 1901. Poverty: A Study of Town Life. Macmillan.

Ryan, Camille L., and Julie Siebens. 2012. Educational Attainment in the United States: 2009. Population Characteristics. Current Population Reports. P20-566. US Census Bureau.

Sandoval, Daniel A., Mark R. Rank, and Thomas A. Hirsch. 2009. "The Increasing Risk of Poverty Across the American Life Course.” Demography 46 (4): 717-37.

Settersten, Richard A., and Karl Ulrich Mayer. 1997. "The Measurement of Age Structuring and the Life Course." Annual Review of Sociology 23: 233-61.

Spini, Dario, Laura Bernardi, and Michel Oris. 2017. "Toward a Life Course Framework for Studying Vulnerability." Research in Human Development 14 (1): 5-25.

Studer, Matthias. 2013. "WeightedCluster Library Manual: A Practical Guide to Creating Typologies of Trajectories in the Social Sciences with R.” 23. LIVES. Lausanne, Switzerland.

Studer, Matthias, and Gilbert Ritschard. 2016. "What Matters in Differences between Life Trajectories: A Comparative Review of Sequence Dissimilarity Measures.” Journal of the Royal Statistical Society: Series A (Statistics in Society) 179 (2): 481-511. 
Studer, Matthias, Emanuela Struffolino, and Anette E. Fasang. 2018. "Estimating the Relationship between Time-Varying Covariates and Trajectories: The Sequence Analysis Multistate Model Procedure.” Sociological Methodology 48: 1-34.

Sweeney, Megan M., and Julie A. Phillips. 2004. "Understanding Racial Differences in Marital Disruption: Recent Trends and Explanations." Journal of Marriage and Family 66 (3): 639-50.

Sweeney, Megan M., and R. Kelly Raley. 2014. "Race, Ethnicity, and the Changing Context of Childbearing in the United States." Annual Review of Sociology 40: 539-58.

Tejero, Aroa. 2017. "In-Work Poverty Persistence: The Influence of Past Poverty on the Present.” Revista Española de Investigaciones Sociológicas (REIS) 157 (157): 14180.

Therneau, Terry M, Patricia M Grambsch, and V. Shane Pankratz. 2003. "Penalized Survival Models and Frailty." Journal of Computational and Graphical Statistics 12 (1): 15675. https://doi.org/10.1198/1061860031365.

Thiede, Brian C., Daniel T. Lichter, and Scott R. Sanders. 2015. “America's Working Poor: Conceptualization, Measurement, and New Estimates." Work and Occupations 42 (3): $267-312$.

Thiede, Brian C., Scott R. Sanders, and Daniel T. Lichter. 2018. "Demographic Drivers of InWork Poverty." In Handbook of In-Work Poverty, edited by Henning Lohmann and Ive Marx, 109-23. Cheltenham, UK/Northampton, MA, USA: Edward Elgar Publishing.

Uunk, Wilfred. 2004. "The Economic Consequences of Divorce for Women in the European Union: The Impact of Welfare State Arrangements." European Journal of Population / Revue Européenne de Démographie 20 (3): 251-85.

Van Winkle, Zachary, and Anette Eva Fasang. 2020. "Parenthood Wage Gaps Across the Life Course: A Comparison by Gender and Race." Journal of Marriage and Family. Van Winkle, Zachary, and Emanuela Struffolino. 2018. “When Working Isn’t Enough: Family Demographic Processes and in-Work Poverty across the Life Course in the United States." Demographic Research 39 (12): 365-80.

Vandecasteele, Leen, and Marco Giesselmann. 2018. "The Dynamics of In-Work Poverty." In Handbook on In-Work Poverty, edited by Henning Lohmann and Ive Marx, 193211. Cheltenham, UK/Northampton, MA, USA: Edward Elgar Publishing. 
Willson, Andrea E. 2003. "Race and Women's Income Trajectories: Employment, Marriage, and Income Security Over the Life Course.” Social Problems 50 (1): 87-110. https://doi.org/10.1525/sp.2003.50.1.87. 
APPENDIX

Tables:

Table A1. Sample distribution

\begin{tabular}{lccc}
\hline & & $\begin{array}{c}\text { Among } \\
\text { men/women }\end{array}$ & $\begin{array}{c}\text { In the total } \\
\text { sample }\end{array}$ \\
\hline Men & 49.16 & & \\
White & & 56.86 & 27.99 \\
Black & & 39.47 & 19.43 \\
Hispanic & 3.67 & 1.81 \\
Women & 50.84 & & \\
White & & 53.83 & 27.33 \\
Black & & 42.56 & 21.61 \\
Hispanic & & 3.61 & 1.83 \\
\hline Tot. col. \% & 100 & 100 & 100 \\
\hline N. Individuals & 21,177 & & \\
\hline
\end{tabular}

Not weighted. Source PSID, 3.14\% of cases are missing on race. 
Table A2: Clusters' composition. (a) row percentages, (b) column percentages

\begin{tabular}{|c|c|c|c|c|c|c|c|c|c|c|c|}
\hline & \multirow{2}{*}{\multicolumn{5}{|c|}{ (a) }} & \multirow[b]{3}{*}{$N^{*}$} & \multirow{2}{*}{\multicolumn{5}{|c|}{$\frac{\text { (b) }}{\text { Cluster }}$}} \\
\hline & & & & & & & & & & & \\
\hline & $\begin{array}{l}\text { 1.Immediate } \\
\text { recovery }\end{array}$ & $\begin{array}{l}\text { 2.Turbulent } \\
\text { recovery }\end{array}$ & $\begin{array}{l}\text { 3.Continuous } \\
\text { vulnerability }\end{array}$ & $\begin{array}{l}\text { 4.Cyclical } \\
\text { in-work } \\
\text { poverty }\end{array}$ & $\begin{array}{l}\text { 5.Impoverished } \\
\text { non- } \\
\text { employment }\end{array}$ & & $\begin{array}{l}\text { 1.Immediate } \\
\text { recovery }\end{array}$ & $\begin{array}{l}\text { 2.Turbulent } \\
\text { recovery }\end{array}$ & $\begin{array}{l}\text { 3.Continuous } \\
\text { vulnerability }\end{array}$ & $\begin{array}{l}\text { 4.Cyclical } \\
\text { in-work } \\
\text { poverty }\end{array}$ & $\begin{array}{c}\text { 5.Impoverished } \\
\text { non- } \\
\text { employment }\end{array}$ \\
\hline \multicolumn{12}{|l|}{ Men } \\
\hline White & 23.0 & 22.9 & 23.9 & 14.8 & 15.5 & 1311 & 31.7 & 36.5 & 32.3 & 37.0 & 32.7 \\
\hline Black & 28.8 & 20.4 & 26.2 & 9.3 & 15.3 & 378 & 11.5 & 9.4 & 10.2 & 6.7 & 9.4 \\
\hline Hispanic & 25.0 & 25.0 & 28.9 & 10.5 & 10.5 & 76 & 2.0 & 2.3 & 2.3 & 1.5 & 1.3 \\
\hline \multicolumn{12}{|l|}{ Women } \\
\hline White & 23.0 & 20.3 & 26.2 & 14.3 & 16.2 & 1393 & 33.6 & 34.5 & 37.7 & 38.0 & 36.5 \\
\hline Black & 27.4 & 20.8 & 22.8 & 11.7 & 17.3 & 624 & 18.0 & 15.8 & 14.7 & 13.9 & 17.4 \\
\hline Hispanic & 30.4 & 11.8 & 26.5 & 14.7 & 16.7 & 102 & 3.3 & 1.5 & 2.8 & 2.9 & 2.7 \\
\hline Years of education** & $12.4(2.3)$ & $12.6(2.1)$ & $12.5(2.3)$ & $12.5(2.1)$ & $12.6(2.2)$ & & & & & & \\
\hline Out of the labor force & 26.6 & 19.0 & 25.4 & 12.8 & 16.1 & & 37.8 & 31.4 & 34.9 & 33.2 & 34.9 \\
\hline Management, Professionals & 22.4 & 21.1 & 27.6 & 13.4 & 15.5 & & 20.2 & 22.1 & 24.0 & 22.0 & 21.4 \\
\hline $\begin{array}{l}\text { Technical, Sales Admin. } \\
\text { Support }\end{array}$ & 22.8 & 23.5 & 20.9 & 15.3 & 17.5 & & 14.2 & 17.1 & 12.7 & 17.4 & 16.7 \\
\hline Service & 23.7 & 23.7 & 28.1 & 9.3 & 15.2 & & 7.3 & 8.5 & 8.4 & 5.2 & 7.1 \\
\hline $\begin{array}{l}\text { Farming, Fishing, Craft, } \\
\text { Production }\end{array}$ & 23.5 & 21.9 & 25.9 & 13.4 & 15.3 & & 11.4 & 12.3 & 12.1 & 11.8 & 11.3 \\
\hline $\begin{array}{l}\text { Operators, Fabricators, } \\
\text { Laborers }\end{array}$ & 25.2 & 20.4 & 23.0 & 15.7 & 15.7 & & 9.1 & 8.6 & 8.0 & 10.4 & 8.7 \\
\hline Experience** & $15.5(8.5)$ & $15.7(8.7)$ & $16.0(8.7)$ & $15.2(8.8)$ & $15.5(8.7)$ & & & & & & \\
\hline \multicolumn{12}{|l|}{ Nr. children $* *$} \\
\hline 0 & 22.8 & 21.6 & 26.7 & 13.6 & 15.3 & & 28.9 & 31.9 & 32.9 & 31.5 & 30.0 \\
\hline 1 & 23.9 & 21.9 & 23.9 & 13.5 & 16.7 & & 23.4 & 25.1 & 22.8 & 24.3 & 25.4 \\
\hline 2 & 26.5 & 19.9 & 25.7 & 11.7 & 16.2 & & 26.0 & 22.8 & 24.5 & 21.1 & 24.8 \\
\hline $3+$ & 25.7 & 20.5 & 23.9 & 14.9 & 15.0 & & 21.8 & 20.3 & 19.7 & 23.2 & 19.8 \\
\hline \multicolumn{12}{|l|}{ Civil status** } \\
\hline Married & 25.3 & 20.6 & 25.1 & 14.0 & 15.0 & & 68.6 & 65.2 & 66.4 & 69.7 & 63.1 \\
\hline Single never married & 22.9 & 22.9 & 25.2 & 11.3 & 17.6 & & 23.7 & 27.7 & 25.4 & 21.5 & 28.3 \\
\hline Separated & 23.7 & 18.6 & 25.9 & 14.8 & 17.0 & & 7.7 & 7.1 & 8.2 & 8.9 & 8.6 \\
\hline Left parental home (yes)** & 24.8 & 20.6 & 25.3 & 13.6 & 15.7 & & 85.2 & 82.6 & 84.8 & 86.1 & 84.2 \\
\hline$N$ & & & & & & & 974 & 834 & 999 & 531 & 626 \\
\hline
\end{tabular}

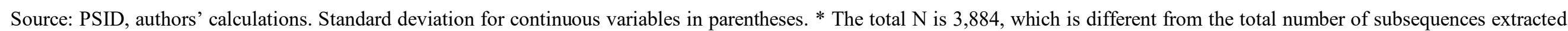
$(3,964)$ because 80 subsequences are extracted from sequences of individuals who are missing on "race". **Measured when the transition out of in-work poverty occurred. 


\section{Figures:}

Figure A1: Proportion of Employed Men and Women in Absolute and Relative Poverty by Race in the United States, 1971-2018

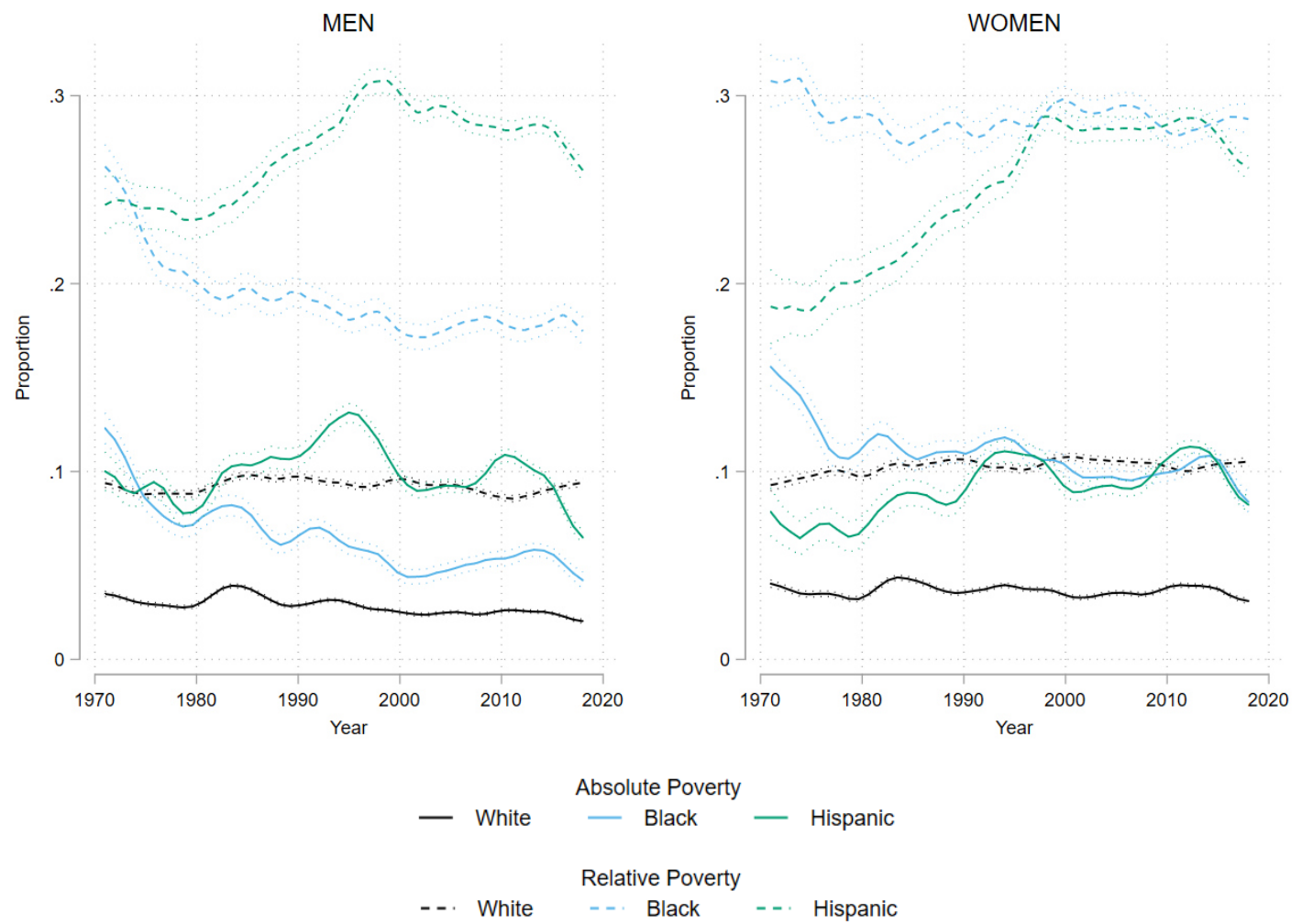

Source: 1971-2018 Current Population Surveys (CPS) and Annual Social and Economic Supplements (ASES); Employment defined as working 27 weeks or more; Proportions and 95\% confidence intervals displayed; Absolute poverty (solid lines) defined as households with gross household incomes below US Census Bureau poverty thresholds; Relative poverty (dashed lines) defined (according to the Eurostat definition) as households with net equivalized household incomes below 60 percent of the median. Data weighted. Authors' calculations.

Note: The major advantage of adopting the two indicators displayed in Figure A1 is that they are both standard measures used by official agencies. The figure shows the proportion of employed men and women by race in the two conditions over time. We opt for these two consolidated and broadly used indicators to identify severe poverty among workers and the condition of at-risk-of in-work poverty respectively. As can be inferred from Figure A1, the absolute poverty threshold is always lower than the relative poverty threshold. Contrasting an absolute and a relative indicator for poverty allows us to contrast conditions of a more and less severe poverty without having to make additional arbitrary decisions on what thresholds to use. 
Figure A2: Summary Statistics on the Relative Frequency Sequence Plots of Pathways Out

\section{of In-Work Poverty Clusters}

1. Immediate recovery $(24.5 \%)$

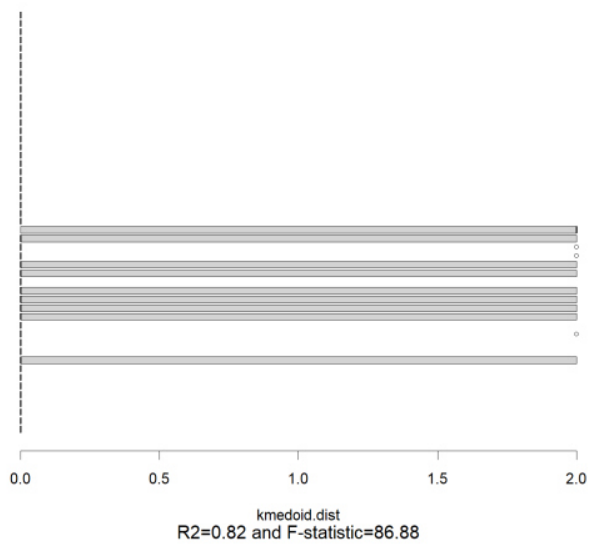

3. Continuous vulnerability $(25.1 \%)$

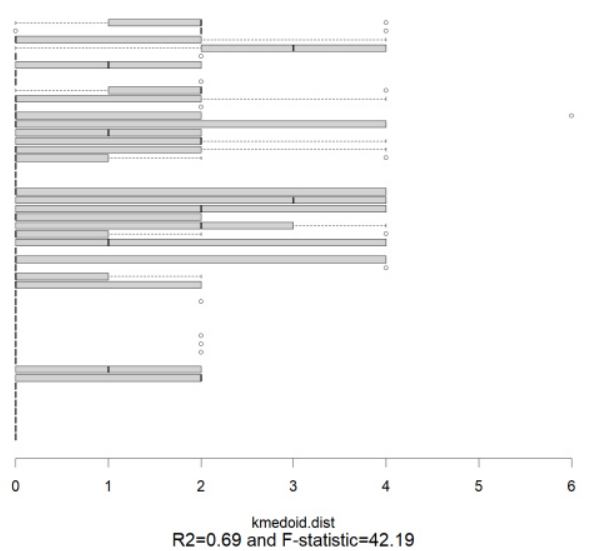

5. Impoverished non-employment (15.8\%)

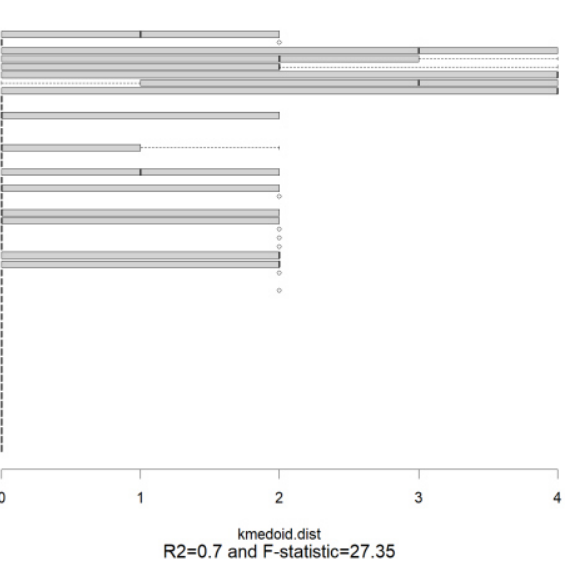

2. Turbulent recovery $(21.2 \%)$

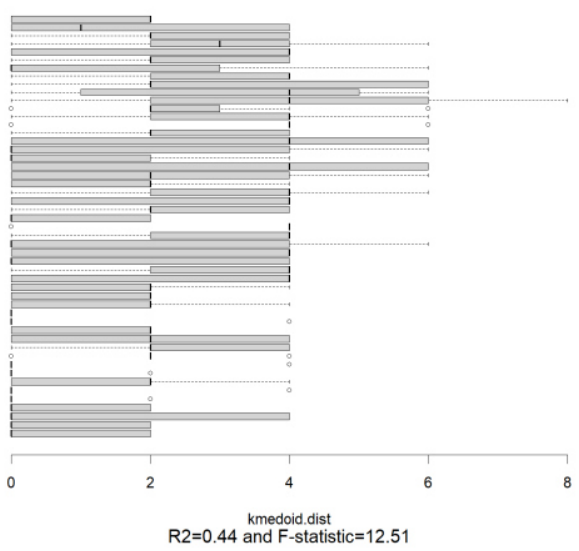

4. Cyclical in-work poverty $(13.4 \%)$

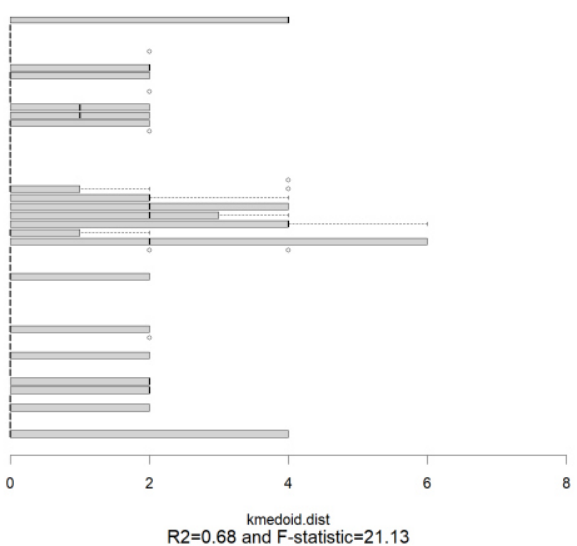

Source: PSID, authors' calculations. The box-and-whisker plots display the dissimilarity to medoid plots for each group of 100 subsequences by cluster. The R2 statistic contrasts distances to frequency group medoids to distances to the general medoid. Based on the relationship between the explained sum of distance (averaged) and the unexplained sum distance (averaged), the $\mathrm{F}$ test assesses whether the chosen sorting principle, distance measure, and the number of medoids to be extracted capture the heterogeneity in the overall sample and successfully summarize the set of sequences visually. In our case, all F-statistic values are significant at the 5 percent level. 
Figure A3: Cluster Membership of Subsequences in Percent of Subsequences Extracted by Age, Period, and Birth Cohort
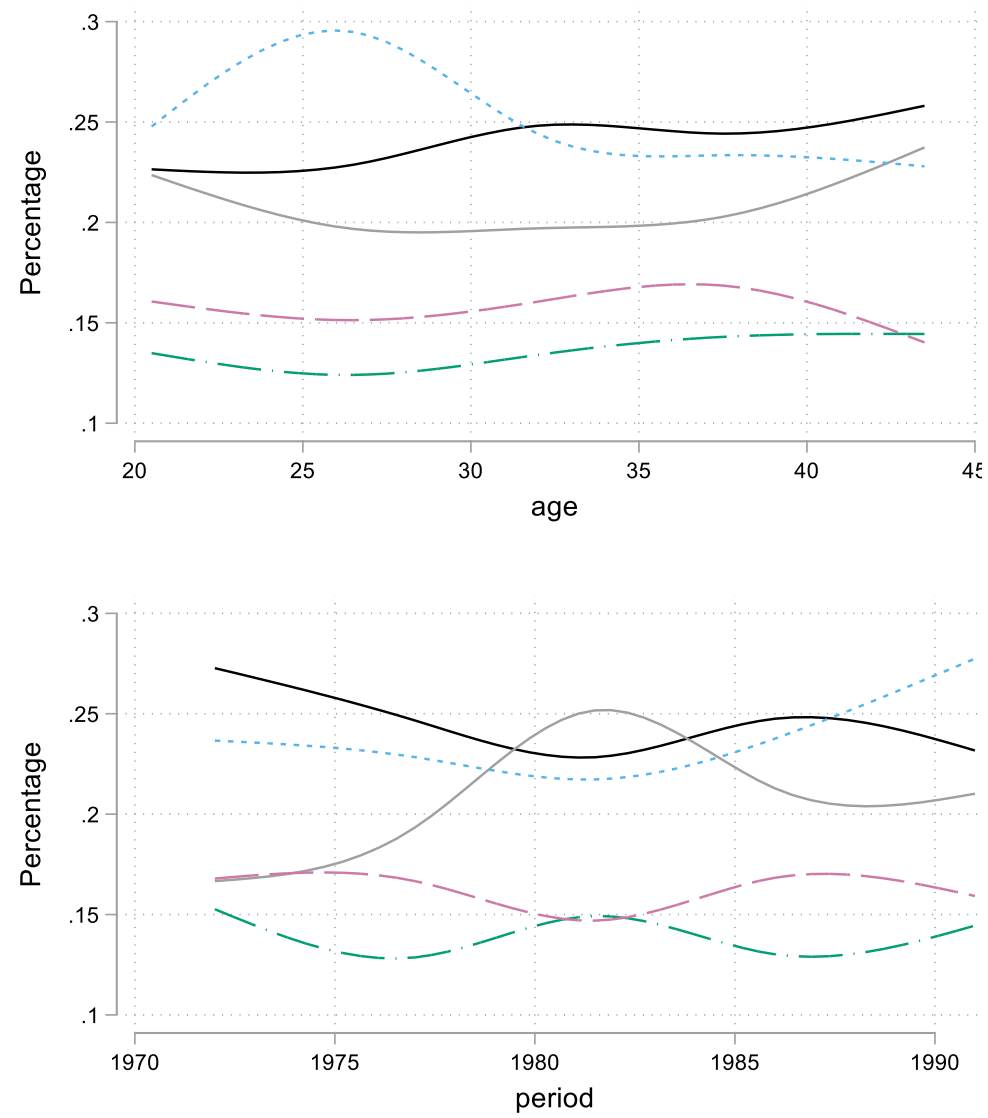

1.Immediate recovery 2.Turbulent recovery

3.Continuous vulnerability

- 4.Cyclical in-work poverty

- 5.Impoverished non-employment

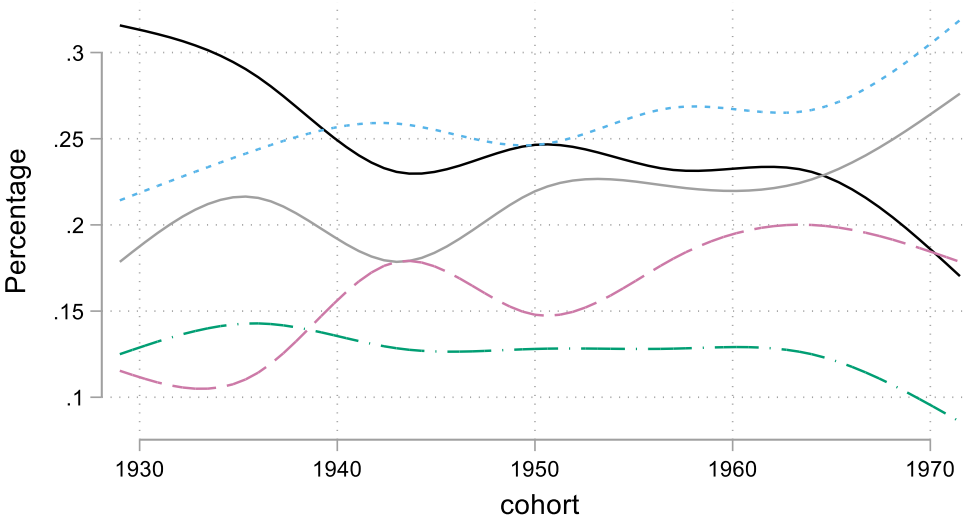

Source: PSID, authors' calculations. 
Figure A4: Example Trajectories of Units in In-Work Poverty for Varying Durations with Varying Pathways Out of In-Work Poverty

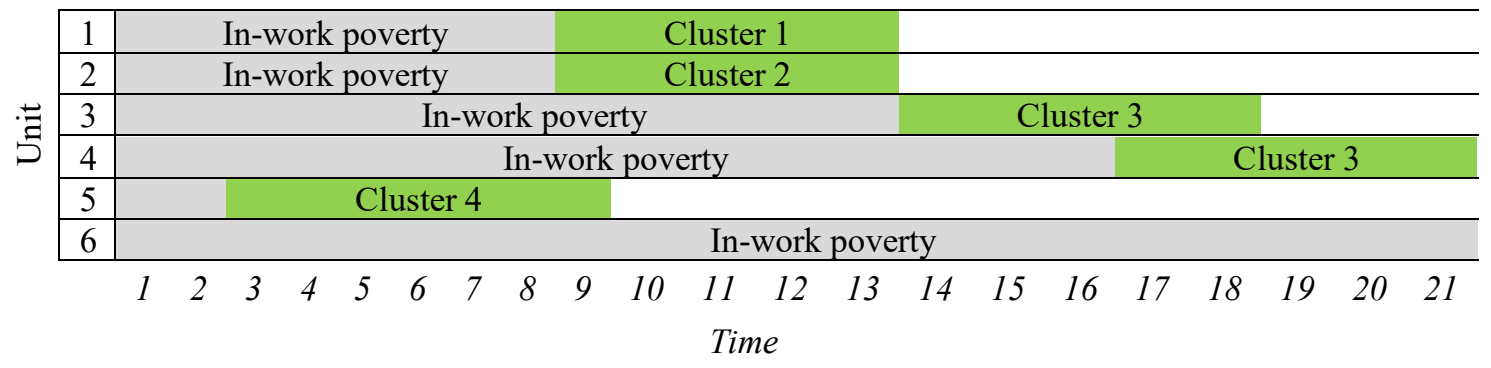

Note: Figure A4 displays six example units (e.g., observations within individuals) over time (e.g., from the first year observed episode in in-work poverty). In the case of the first two units, the individuals they correspond to spend an equal amount of time in in-work poverty, but exit through two different clusters, cluster 1 and cluster 2 . The third and fourth unit spend an even longer duration within in-work poverty, although different, but exit into the same cluster 3 . The first unit is only in in-work poverty for one year before exiting into cluster 4 . Finally, the sixth unit does not exit in-work poverty at all. All six units are modelled in our hazard regressions, because they all spend time in in-work poverty. However, and most importantly, the durations each unit spends in in-work poverty before exiting-or not exiting at all-differs. We are not just modelling the probability of exiting into one cluster or the other, but also modelling the time spent within inwork poverty before doing so. While the prevalence of clusters may be equal over time-although that is an empirical question-the time spend in in-work poverty before exiting may differ depending on the cluster and individual characteristic, both time invariant and variant. 


\section{SUPPLEMENTS}

\section{Supplement A: Cox Proportional Hazards Regression on Exiting In-Work Poverty}

To highlight the added value of our analytical strategy, we estimated Cox regressions on the hazard rate of exiting in-work poverty. The coefficients of these models represent changes in the hazard to leave the state "working and poor" regardless of the following state. These results are available upon request.

In the baseline models, we see that Black and Hispanic men as well as Black women have a lower propensity to exit in-work poverty compared to white men. The survival curves by gender and race displayed in Figure A1 in Supplement A demonstrate that differences emerge relatively early, but diminish after 4 years within in-work poverty. Nearly 80 percent of white men exit in-work poverty within one year, while only 70 percent of Black and Hispanic men and only 60 percent of Black women escape in-work poverty within a year. These differences, in the magnitude of roughly 10 percentage points, remain until the fifth year within in-work poverty. Nearly all individuals, regardless of gender or race, exit in-work poverty after six years. These differences, although small and attenuated slightly, remain statistically significant even after controlling for both labor market related factors and family demographic behavior.

In sum, we do observe some gender and race disparities in the timing and propensity to exit in-work poverty. Further, these disparities cannot be completely attributed to compositional differences. However, the gender and race differences in the hazard of exiting in-work poverty give us no indication of what happens to individuals in the years following their exit out of in-work poverty. A fast exit out of in-work poverty does not necessarily mean recovery, for example, if individuals exit the labor force, but continue to live in impoverished households or regress into another spell of in-work poverty. As a matter of fact, these results can only convey information on whether in-work poverty represents a 
shorter or longer phase in individuals' lives and whether there are differences by gender and race.

Figure A1: Kaplan-Meier Survival Estimates on Exiting In-Work Poverty by Gender and Race
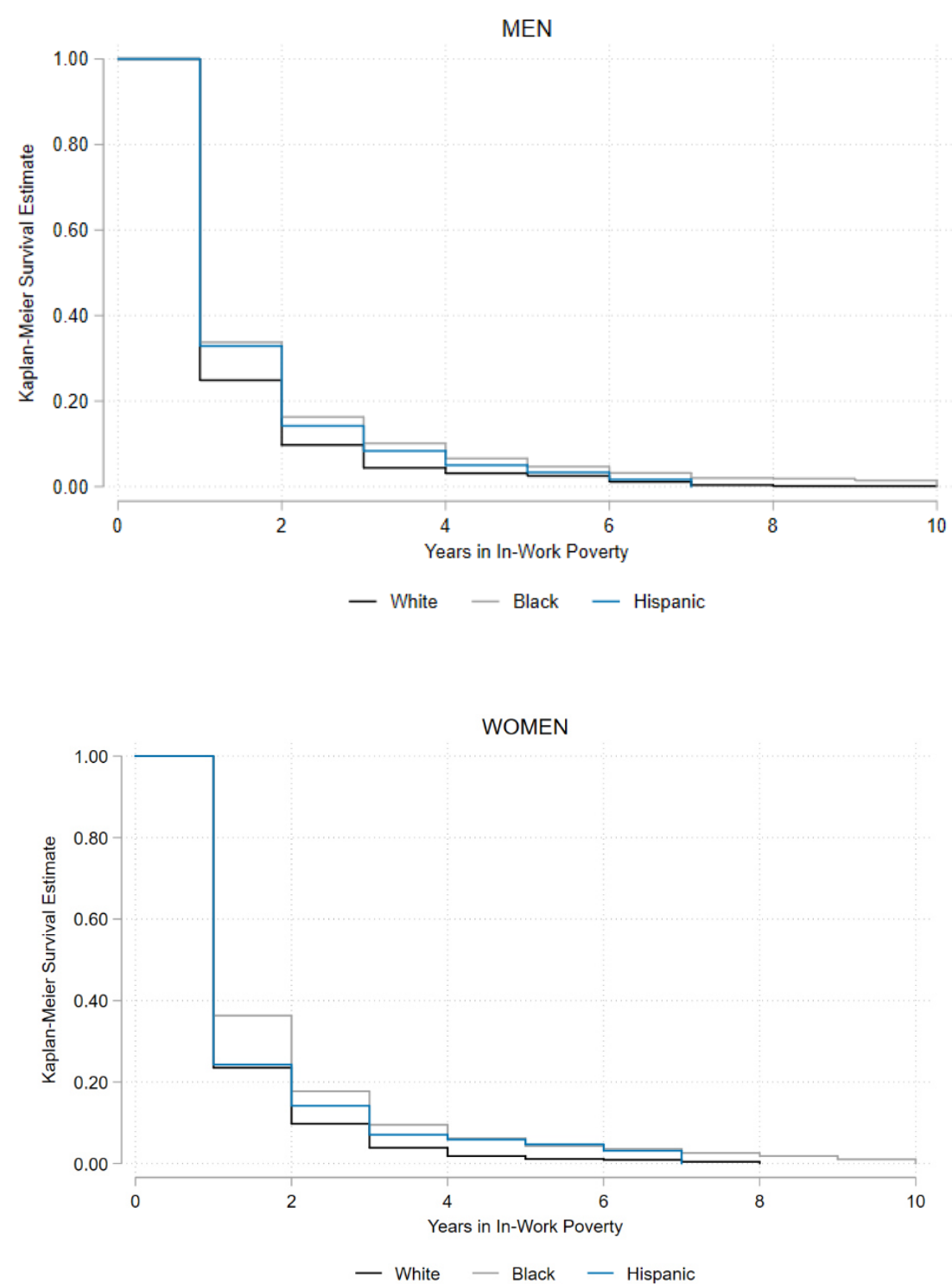

Note: Differences between subject groups not statistically significant with the exception of white men compared to others after 6 years within in-work poverty. Source: PSID. 
Table A1. Stepwise Cox models for the hazard of leaving in-work poverty

\begin{tabular}{|c|c|c|c|c|c|}
\hline & Model 1 & Model 2 & Model 3 & Model 4 & Model 5 \\
\hline Black Men ${ }^{1}$ & $\begin{array}{c}-0.15 * * * \\
(0.03)\end{array}$ & $\begin{array}{c}-0.14 * * * \\
(0.03)\end{array}$ & $\begin{array}{c}-0.11 * * * \\
(0.03)\end{array}$ & $\begin{array}{c}-0.14 * * * \\
(0.03)\end{array}$ & $\begin{array}{c}-0.11 * * * \\
(0.03)\end{array}$ \\
\hline Hispanic Men ${ }^{1}$ & $\begin{array}{l}-0.06 \\
(0.05)\end{array}$ & $\begin{array}{l}-0.02 \\
(0.05)\end{array}$ & $\begin{array}{c}0.00 \\
(0.05)\end{array}$ & $\begin{array}{l}-0.02 \\
(0.05)\end{array}$ & $\begin{array}{c}0.00 \\
(0.05)\end{array}$ \\
\hline White Women ${ }^{1}$ & $\begin{array}{c}0.05 \\
(0.03)\end{array}$ & $\begin{array}{c}0.02 \\
(0.03)\end{array}$ & $\begin{array}{l}-0.01 \\
(0.03)\end{array}$ & $\begin{array}{c}0.02 \\
(0.03)\end{array}$ & $\begin{array}{l}-0.00 \\
(0.03)\end{array}$ \\
\hline Black Women ${ }^{1}$ & $\begin{array}{c}-0.11 * * * \\
(0.02)\end{array}$ & $\begin{array}{c}-0.14 * * * \\
(0.02)\end{array}$ & $\begin{array}{c}-0.15 * * * \\
(0.02)\end{array}$ & $\begin{array}{c}-0.12 * * * \\
(0.03)\end{array}$ & $\begin{array}{c}-0.13 * * * \\
(0.03)\end{array}$ \\
\hline Hispanic Women ${ }^{1}$ & $\begin{array}{c}0.01 \\
(0.06)\end{array}$ & $\begin{array}{c}0.02 \\
(0.06)\end{array}$ & $\begin{array}{c}0.02 \\
(0.06)\end{array}$ & $\begin{array}{c}0.03 \\
(0.06)\end{array}$ & $\begin{array}{c}0.03 \\
(0.06)\end{array}$ \\
\hline Years of education & & & $\begin{array}{c}0.04 * * * \\
(0.00)\end{array}$ & & $\begin{array}{c}0.03 * * * \\
(0.00)\end{array}$ \\
\hline Management, Professionals ${ }^{2}$ & & & $\begin{array}{c}0.03 \\
(0.03)\end{array}$ & & $\begin{array}{c}0.03 \\
(0.03)\end{array}$ \\
\hline Technical, Sales Admin. Support ${ }^{2}$ & & & $\begin{array}{c}0.05 \\
(0.03)\end{array}$ & & $\begin{array}{c}0.04 \\
(0.03)\end{array}$ \\
\hline Service $^{2}$ & & & $\begin{array}{l}-0.06^{*} \\
(0.03)\end{array}$ & & $\begin{array}{c}-0.07 * * \\
(0.03)\end{array}$ \\
\hline $\begin{array}{l}\text { Farming, Fishing, Craft, } \\
\text { Production }^{2}\end{array}$ & & & $\begin{array}{l}-0.07 * \\
(0.03)\end{array}$ & & $\begin{array}{l}-0.08^{*} \\
(0.03)\end{array}$ \\
\hline Operators, Fabricators, Laborers ${ }^{2}$ & & & $\begin{array}{l}-0.02 \\
(0.03)\end{array}$ & & $\begin{array}{l}-0.03 \\
(0.03)\end{array}$ \\
\hline Experience & & & $\begin{array}{l}-0.00 \\
(0.00)\end{array}$ & & $\begin{array}{l}-0.00 \\
(0.00)\end{array}$ \\
\hline 1 child $^{3}$ & & & & $\begin{array}{l}-0.01 \\
(0.02)\end{array}$ & $\begin{array}{c}0.01 \\
(0.02)\end{array}$ \\
\hline 2 children $^{3}$ & & & & $\begin{array}{c}-0.09 * * * \\
(0.03)\end{array}$ & $\begin{array}{c}-0.07 * * \\
(0.03)\end{array}$ \\
\hline $3+$ children $^{3}$ & & & & $\begin{array}{c}-0.14 * * * \\
(0.03)\end{array}$ & $\begin{array}{c}-0.12 * * * \\
(0.03)\end{array}$ \\
\hline Single never married ${ }^{4}$ & & & & $\begin{array}{l}-0.01 \\
(0.03)\end{array}$ & $\begin{array}{l}-0.02 \\
(0.03)\end{array}$ \\
\hline Separated $^{4}$ & & & & $\begin{array}{l}-0.02 \\
(0.03)\end{array}$ & $\begin{array}{l}-0.02 \\
(0.03)\end{array}$ \\
\hline Left parental home & & & & $\begin{array}{l}-0.02 \\
(0.04)\end{array}$ & $\begin{array}{l}-0.03 \\
(0.04)\end{array}$ \\
\hline $\mathrm{N}_{\text {Subjects }}$ & 3,564 & 3,564 & 3,564 & 3,564 & 3,564 \\
\hline Nobservations & 5,329 & 5,329 & 5,329 & 5,329 & 5,329 \\
\hline $\mathrm{N}_{\text {Failures }}$ & 5,045 & 5,045 & 5,045 & 5,045 & 5,045 \\
\hline
\end{tabular}

Note: Sig.: ${ }^{* * *} \mathrm{p}<0.001,{ }^{* *} \mathrm{p}<0.01,{ }^{*} \mathrm{p}<0.05$; Reference categories: ${ }^{1}$ White men, ${ }^{2}$ Military or out of the labor force, ${ }^{3}$ Childless, ${ }^{4}$ Married; All models control for number of earners in the household, year of birth, age, age-squared, time. Source: PSID. 


\section{Supplement B: Competing Risk Mixed Cox Proportional Hazards Models}

Table B1: Competing risk Cox model for the probability of leaving in-work poverty through one of the five pathways: gender and race

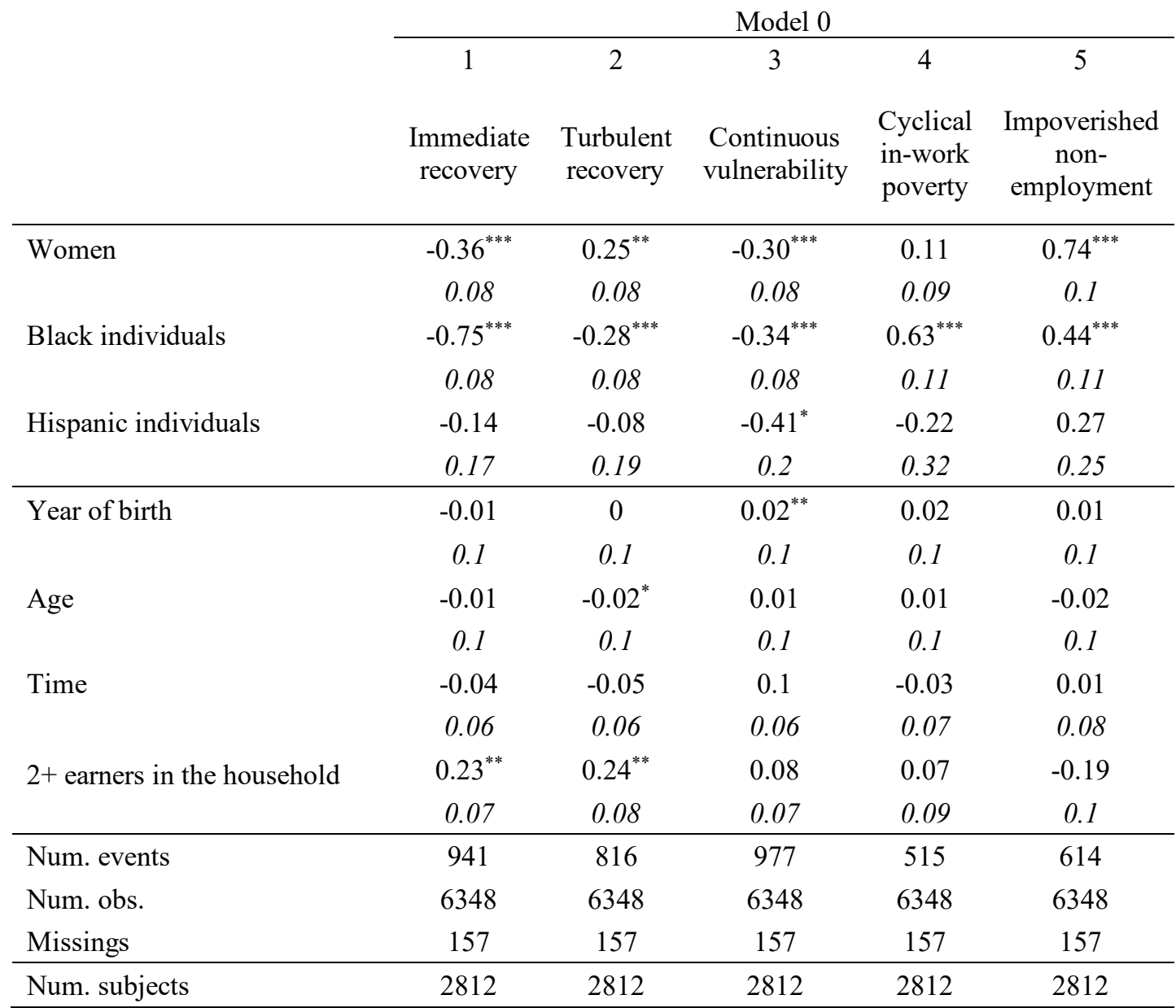

Note: $\operatorname{Sig} .:{ }^{* * *} \mathrm{p}<0.001,{ }^{* *} \mathrm{p}<0.01,{ }^{*} \mathrm{p}<0.05$; standard errors in italics. Reference categories: ${ }^{1} \mathrm{Men},{ }^{2} \mathrm{White}$ individuals, ${ }^{3}$ Military or out of the labor force, ${ }^{4}$ Childless, ${ }^{5}$ Married; ${ }^{6}$ One earner in the household. Source: PSID. 
Table B2: Competing risk Cox model for the probability of leaving in-work poverty through one of the five pathways: gender by race

\begin{tabular}{lccccc} 
& \multicolumn{6}{c}{ Model 1 } \\
\cline { 2 - 6 } & 1 & 2 & 3 & 4 & 5 \\
\cline { 2 - 6 } & $\begin{array}{c}\text { Immediate } \\
\text { recovery }\end{array}$ & $\begin{array}{c}\text { Turbulent } \\
\text { recovery }\end{array}$ & $\begin{array}{c}\text { Continuous } \\
\text { vulnerability }\end{array}$ & $\begin{array}{c}\text { Cyclical } \\
\text { in-work } \\
\text { poverty }\end{array}$ & $\begin{array}{c}\text { Impoverished } \\
\text { non- } \\
\text { employment }\end{array}$ \\
\hline Black men $^{1}$ & $-0.69^{* * *}$ & 0.01 & $-0.37^{* * *}$ & $0.51^{* * *}$ & $0.56^{* * *}$ \\
& 0.1 & 0.12 & 0.1 & 0.15 & 0.17 \\
Hispanic men & -0.15 & -0.24 & -0.32 & 0 & 0.22 \\
& 0.22 & 0.29 & 0.25 & 0.38 & 0.4 \\
White women $^{1}$ & $-0.28^{*}$ & $0.57^{* * *}$ & $-0.33^{*}$ & -0.09 & $0.89^{* * *}$ \\
Black women $^{1}$ & 0.12 & 0.13 & 0.13 & 0.21 & 0.19 \\
& $-1.12^{* * *}$ & 0.01 & $-0.63^{* * *}$ & $0.69^{* * *}$ & $1.24^{* * *}$ \\
Hispanic women $^{1}$ & 0.11 & 0.11 & 0.1 & 0.14 & 0.16 \\
& -0.41 & $0.60^{*}$ & $-0.90^{* *}$ & -0.71 & $1.19^{* * *}$ \\
& 0.27 & 0.26 & 0.33 & 0.59 & 0.34 \\
\hline
\end{tabular}

Years of education

Management, Professionals ${ }^{2}$

Technical, Sales Admin. Support ${ }^{2}$

Service ${ }^{2}$

Farming, Fishing, Craft,

Production $^{2}$

Operators, Fabricators, Laborers ${ }^{2}$

Experience

1 child $^{3}$
2 children $^{3}$
$3+$ children $^{3}$

Single never married ${ }^{4}$

Separated $^{4}$

Left parental home

\begin{tabular}{lccccc}
\hline Mills Ratio & & & & & \\
\hline Year of birth & -0.01 & 0 & $0.02^{* *}$ & 0.02 & 0.01 \\
& 0.01 & 0.01 & 0.01 & 0.01 & 0.01 \\
Age & -0.01 & -0.02 & 0 & 0.01 & -0.02 \\
& 0.01 & 0.01 & 0.01 & 0.01 & 0.01 \\
Time & -0.04 & -0.05 & 0.1 & -0.03 & 0.01 \\
& 0.06 & 0.06 & 0.06 & 0.07 & 0.08 \\
$2+$ earners in the household & $0.23^{* *}$ & $0.23^{* *}$ & 0.08 & 0.07 & -0.19 \\
& 0.07 & 0.08 & 0.07 & 0.09 & 0.01 \\
\hline Num. events & 941 & 816 & 977 & 515 & 614 \\
Num. obs. & 6348 & 6348 & 6348 & 6348 & 6348 \\
Missing & 157 & 157 & 157 & 157 & 157 \\
\hline Num. subjects & 2812 & 2812 & 2812 & 2812 & 2812 \\
\hline
\end{tabular}


Table B1, continued

Model 2

\begin{tabular}{|c|c|c|c|c|c|}
\hline & \multicolumn{5}{|c|}{ Model 2} \\
\hline & 1 & 2 & 3 & 4 & 5 \\
\hline & $\begin{array}{l}\text { Immediate } \\
\text { recovery }\end{array}$ & $\begin{array}{l}\text { Turbulent } \\
\text { recovery }\end{array}$ & $\begin{array}{l}\text { Continuous } \\
\text { vulnerability }\end{array}$ & $\begin{array}{l}\text { Cyclical } \\
\text { in-work } \\
\text { poverty }\end{array}$ & $\begin{array}{c}\text { Impoverished } \\
\text { non- } \\
\text { employment }\end{array}$ \\
\hline \multirow{2}{*}{ Black men $^{1}$} & $-0.54^{* * *}$ & 0.11 & $-0.33^{* *}$ & $0.46^{* *}$ & $0.55^{* *}$ \\
\hline & 0.1 & 0.12 & 0.1 & 0.15 & 0.17 \\
\hline \multirow[t]{2}{*}{ Hispanic men ${ }^{1}$} & -0.01 & -0.14 & -0.28 & -0.05 & 0.21 \\
\hline & 0.21 & 0.29 & 0.25 & 0.38 & 0.4 \\
\hline \multirow[t]{2}{*}{ White women ${ }^{1}$} & $-0.28^{*}$ & $0.56^{* * *}$ & $-0.33^{*}$ & -0.1 & $0.89^{* * *}$ \\
\hline & 0.12 & 0.13 & 0.13 & 0.21 & 0.19 \\
\hline \multirow[t]{2}{*}{ Black women ${ }^{1}$} & $-0.93^{* * *}$ & 0.14 & $-0.58^{* * *}$ & $0.63^{* * *}$ & $1.22^{* * *}$ \\
\hline & 0.11 & 0.12 & 0.11 & 0.15 & 0.16 \\
\hline \multirow[t]{2}{*}{ Hispanic women $^{1}$} & -0.25 & $0.70^{* *}$ & $-0.85^{*}$ & -0.77 & $1.17^{* * *}$ \\
\hline & 0.27 & 0.26 & 0.33 & 0.59 & 0.34 \\
\hline
\end{tabular}

Years of education

Management, Professionals ${ }^{2}$

Technical, Sales Admin. Support ${ }^{2}$

Service ${ }^{2}$

Farming, Fishing, Craft, Production ${ }^{2}$

Operators, Fabricators, Laborers ${ }^{2}$

Experience

1 child $^{3}$
2 children $^{3}$
$3+$ children $^{3}$

Single never married ${ }^{4}$

Separated $^{4}$

Left parental home

\begin{tabular}{lccccc}
\hline Mills Ratio & $0.46^{* * *}$ & $0.35^{* * *}$ & 0.15 & -0.18 & -0.04 \\
& 0.07 & 0.08 & 0.08 & 0.1 & 0.09 \\
\hline Year of birth & -0.01 & 0 & $0.02^{* *}$ & 0.02 & 0.01 \\
& 0.01 & 0.01 & 0.01 & 0.01 & 0.01 \\
Age & 0 & -0.02 & 0.01 & 0.01 & -0.02 \\
& 0.01 & 0.01 & 0.01 & 0.01 & 0.01 \\
Time & -0.1 & -0.09 & 0.09 & -0.01 & 0.01 \\
& 0.06 & 0.06 & 0.06 & 0.07 & 0.08 \\
2+ earners in the household & 0.03 & 0.08 & 0.02 & 0.15 & -0.17 \\
& 0.08 & 0.08 & 0.08 & 0.01 & 0.01 \\
\hline Num. events & 941 & 816 & 977 & 515 & 614 \\
Num. obs. & 6348 & 6348 & 6348 & 6348 & 6348 \\
Missing & 157 & 157 & 157 & 157 & 157 \\
\hline Num. subjects & 2812 & 2812 & 2812 & 2812 & 2812 \\
\hline
\end{tabular}


Table B1, continued

Model 3

\begin{tabular}{|c|c|c|c|c|c|}
\hline & & & & & \\
\hline & 1 & 2 & 3 & 4 & 5 \\
\hline & $\begin{array}{c}\text { Immediate } \\
\text { recovery }\end{array}$ & $\begin{array}{l}\text { Turbulent } \\
\text { recovery }\end{array}$ & $\begin{array}{l}\text { Continuous } \\
\text { vulnerability }\end{array}$ & $\begin{array}{l}\text { Cyclical } \\
\text { in-work } \\
\text { poverty }\end{array}$ & $\begin{array}{c}\text { Impoverished } \\
\text { non- } \\
\text { employment }\end{array}$ \\
\hline \multirow[t]{2}{*}{ Black men ${ }^{1}$} & $-0.30^{* *}$ & 0.14 & $-0.26^{*}$ & $0.33^{*}$ & $0.36^{*}$ \\
\hline & 0.1 & 0.12 & 0.1 & 0.15 & 0.18 \\
\hline \multirow[t]{2}{*}{ Hispanic men ${ }^{1}$} & 0.11 & -0.03 & -0.21 & -0.09 & 0.03 \\
\hline & 0.22 & 0.29 & 0.26 & 0.38 & 0.42 \\
\hline \multirow{2}{*}{ White women ${ }^{1}$} & -0.18 & $0.49^{* * *}$ & -0.23 & -0.18 & $0.68^{* * *}$ \\
\hline & 0.12 & 0.14 & 0.14 & 0.22 & 0.19 \\
\hline \multirow[t]{2}{*}{ Black women $^{1}$} & $-0.80^{* * *}$ & 0.12 & $-0.42^{* * *}$ & $0.53^{* * *}$ & $0.99^{* * *}$ \\
\hline & 0.12 & 0.13 & 0.12 & 0.15 & 0.17 \\
\hline \multirow[t]{2}{*}{ Hispanic women $^{1}$} & -0.08 & $0.63^{*}$ & $-0.69^{*}$ & -0.93 & $0.83^{*}$ \\
\hline & 0.27 & 0.27 & 0.34 & 0.6 & 0.33 \\
\hline \multirow{2}{*}{ Years of education } & $0.12^{* * *}$ & $0.06^{*}$ & $0.08^{* * *}$ & -0.05 & $-0.11^{* * *}$ \\
\hline & 0.02 & 0.02 & 0.02 & 0.03 & 0.02 \\
\hline \multirow[t]{2}{*}{ Management, Professionals ${ }^{2}$} & $0.97^{* * *}$ & $-0.65^{* * *}$ & $0.47^{* * *}$ & $-0.44^{*}$ & $-1.76^{* * *}$ \\
\hline & 0.13 & 0.17 & 0.14 & 0.21 & 0.25 \\
\hline \multirow{2}{*}{ Technical, Sales Admin. Support ${ }^{2}$} & $1.02^{* * *}$ & $-0.52^{* * *}$ & $0.44^{* *}$ & $-1.01^{* * *}$ & $-1.77^{* * *}$ \\
\hline & 0.13 & 0.15 & 0.14 & 0.24 & 0.22 \\
\hline \multirow[t]{2}{*}{ Service $^{2}$} & $0.32^{*}$ & $-0.71^{* * *}$ & $0.27^{*}$ & $-0.37^{* *}$ & $-1.69^{* * *}$ \\
\hline & 0.13 & 0.13 & -0.12 & 0.13 & 0.16 \\
\hline \multirow{2}{*}{ Farming, Fishing, Craft, Production ${ }^{2}$} & $0.85^{* * *}$ & $-0.74^{* * *}$ & $0.47^{* * *}$ & $-0.88^{* * *}$ & $-2.36^{* * *}$ \\
\hline & 0.12 & 0.15 & 0.12 & 0.17 & 0.26 \\
\hline \multirow[t]{2}{*}{ Operators, Fabricators, Laborers ${ }^{2}$} & $0.53^{* * *}$ & $-0.31^{*}$ & $0.55^{* * *}$ & $-0.35^{*}$ & $-1.58^{* * *}$ \\
\hline & 0.12 & 0.12 & 0.11 & 0.14 & 0.19 \\
\hline \multirow[t]{2}{*}{ Experience } & -0.01 & -0.01 & $0.02^{*}$ & 0.02 & -0.02 \\
\hline & 0.1 & 0.1 & 0.1 & 0.1 & 0.1 \\
\hline \multicolumn{6}{|l|}{1 child $^{3}$} \\
\hline \multicolumn{6}{|l|}{2 children $^{3}$} \\
\hline \multicolumn{6}{|l|}{$3+$ children $^{3}$} \\
\hline \multicolumn{6}{|l|}{ Single never married ${ }^{4}$} \\
\hline \multicolumn{6}{|l|}{ Separated $^{4}$} \\
\hline \multicolumn{6}{|l|}{ Left parental home } \\
\hline \multirow[t]{2}{*}{ Mills Ratio } & $0.46^{* * *}$ & $0.33^{* * *}$ & $0.17^{*}$ & -0.15 & -0.1 \\
\hline & 0.07 & 0.08 & 0.08 & 0.11 & 0.1 \\
\hline \multirow[t]{2}{*}{ Year of birth } & $-0.04^{* * *}$ & 0.01 & 0 & $0.03^{* *}$ & $0.06^{* * *}$ \\
\hline & 0.01 & 0.01 & 0.01 & 0.01 & 0.01 \\
\hline \multirow[t]{2}{*}{ Age } & -0.02 & 0.01 & -0.04 & 0 & $0.05^{*}$ \\
\hline & 0.02 & 0.02 & 0.02 & 0.02 & 0.02 \\
\hline Time & -0.11 & -0.1 & 0.12 & 0.06 & -0.02 \\
\hline & 0.06 & 0.07 & 0.07 & 0.08 & 0.09 \\
\hline $2+$ earners in the household ${ }^{5}$ & 0.06 & 0.12 & 0.05 & 0.13 & -0.11 \\
\hline & 0.08 & 0.09 & 0.08 & 0.11 & 0.11 \\
\hline Num. events & 870 & 754 & 939 & 491 & 591 \\
\hline Num. obs. & 6033 & 6033 & 6033 & 6033 & 6033 \\
\hline Missing & 472 & 472 & 472 & 472 & 472 \\
\hline Num. subjects & 2630 & 2630 & 2630 & 2630 & 2630 \\
\hline
\end{tabular}


Table B1 continued

\begin{tabular}{|c|c|c|c|c|c|}
\hline & \multicolumn{5}{|c|}{ Model 4} \\
\hline & 1 & 2 & 3 & 4 & 5 \\
\hline & $\begin{array}{l}\text { Immediate } \\
\text { recovery }\end{array}$ & $\begin{array}{l}\text { Turbulent } \\
\text { recovery }\end{array}$ & $\begin{array}{l}\text { Continuous } \\
\text { vulnerability }\end{array}$ & $\begin{array}{l}\text { Cyclical } \\
\text { in-work } \\
\text { poverty }\end{array}$ & $\begin{array}{l}\text { Impoverished } \\
\text { non- } \\
\text { employment }\end{array}$ \\
\hline \multirow[t]{2}{*}{ Black men $^{1}$} & $-0.60^{* * *}$ & 0.08 & $-0.29^{* *}$ & $0.50^{* *}$ & $0.52^{* *}$ \\
\hline & 0.1 & 0.12 & 0.1 & 0.15 & 0.17 \\
\hline \multirow[t]{2}{*}{ Hispanic men ${ }^{1}$} & -0.03 & -0.15 & -0.24 & -0.04 & 0.21 \\
\hline & 0.21 & 0.29 & 0.25 & 0.38 & 0.4 \\
\hline \multirow[t]{2}{*}{ White women ${ }^{1}$} & $-0.28^{*}$ & $0.54^{* * *}$ & $-0.39^{* *}$ & -0.04 & $0.86^{* * *}$ \\
\hline & 0.12 & 0.13 & 0.13 & 0.22 & 0.19 \\
\hline \multirow[t]{2}{*}{ Black women $^{1}$} & $-0.97^{* * *}$ & 0.13 & $-0.62^{* * *}$ & $0.73^{* * *}$ & $1.13^{* * *}$ \\
\hline & 0.12 & 0.13 & 0.12 & 0.16 & 0.18 \\
\hline \multirow[t]{2}{*}{ Hispanic women $^{1}$} & -0.29 & $0.67^{*}$ & $-0.85^{*}$ & -0.68 & $1.13^{* * *}$ \\
\hline & 0.27 & 0.26 & 0.34 & 0.6 & -0.34 \\
\hline \multicolumn{6}{|l|}{ Years of education } \\
\hline \multicolumn{6}{|l|}{ Management, Professionals ${ }^{2}$} \\
\hline \multicolumn{6}{|c|}{ Technical, Sales Admin. Support ${ }^{2}$} \\
\hline \multicolumn{6}{|c|}{ Service $^{2}$} \\
\hline \multicolumn{6}{|c|}{ Farming, Fishing, Craft, Production ${ }^{2}$} \\
\hline \multicolumn{6}{|c|}{ Operators, Fabricators, Laborers ${ }^{2}$} \\
\hline \multicolumn{6}{|l|}{ Experience } \\
\hline \multirow[t]{2}{*}{1 child $^{3}$} & -0.17 & $-0.37^{* *}$ & $0.33^{* *}$ & 0.01 & 0.15 \\
\hline & 0.12 & 0.12 & 0.12 & 0.17 & 0.14 \\
\hline \multirow[t]{2}{*}{2 children $^{3}$} & $-0.35^{* *}$ & $-0.35^{* *}$ & 0.1 & 0.18 & -0.1 \\
\hline & 0.12 & 0.12 & 0.12 & 0.16 & 0.15 \\
\hline \multirow[t]{2}{*}{$3+$ children $^{3}$} & $-0.25^{*}$ & $-0.47^{* * *}$ & $-0.30^{*}$ & 0.01 & 0 \\
\hline & 0.12 & 0.12 & 0.13 & -0.16 & 0.15 \\
\hline \multirow[t]{2}{*}{ Single never married ${ }^{4}$} & 0.03 & -0.03 & 0.07 & -0.12 & 0.25 \\
\hline & 0.12 & 0.12 & 0.12 & 0.15 & 0.15 \\
\hline \multirow[t]{2}{*}{ Separated $^{4}$} & -0.01 & 0.06 & 0.13 & -0.15 & 0.04 \\
\hline & 0.12 & 0.12 & 0.12 & 0.15 & 0.15 \\
\hline \multirow[t]{2}{*}{ Left parental home } & $-0.63^{* * *}$ & $-0.35^{*}$ & $0.79^{* * *}$ & 0.18 & 0.09 \\
\hline & 0.14 & 0.14 & 0.19 & 0.2 & 0.17 \\
\hline \multirow[t]{2}{*}{ Mills Ratio } & $0.43^{* * *}$ & $0.27^{* *}$ & 0.03 & -0.19 & -0.07 \\
\hline & 0.08 & 0.08 & 0.08 & 0.11 & 0.1 \\
\hline \multirow[t]{2}{*}{ Year of birth } & -0.01 & 0 & $0.02^{*}$ & 0.02 & 0 \\
\hline & 0.01 & 0.01 & 0.01 & 0.01 & 0.01 \\
\hline \multirow[t]{2}{*}{ Age } & 0 & -0.02 & 0 & 0.01 & -0.02 \\
\hline & 0.01 & 0.01 & 0.01 & 0.01 & 0.01 \\
\hline Time & -0.09 & -0.08 & 0.09 & -0.01 & 0.02 \\
\hline & 0.06 & 0.06 & 0.06 & 0.07 & 0.08 \\
\hline $2+$ earners in the household ${ }^{5}$ & 0.02 & 0.16 & $0.20^{*}$ & 0.13 & -0.1 \\
\hline & 0.09 & 0.11 & 0.09 & 0.12 & 0.12 \\
\hline Num. events & 941 & 816 & 977 & 515 & 614 \\
\hline Num. obs. & 6348 & 6348 & 6348 & 6348 & 6348 \\
\hline Missing & 157 & 157 & 157 & 157 & 157 \\
\hline Num. subjects & 2812 & 2812 & 2812 & 2812 & 2812 \\
\hline
\end{tabular}


Table B1 continued

\begin{tabular}{|c|c|c|c|c|c|}
\hline & \multicolumn{5}{|c|}{ Model 5} \\
\hline & 1 & 2 & 3 & 4 & 5 \\
\hline & $\begin{array}{l}\text { Immediate } \\
\text { recovery }\end{array}$ & $\begin{array}{l}\text { Turbulent } \\
\text { recovery }\end{array}$ & $\begin{array}{l}\text { Continuous } \\
\text { vulnerability }\end{array}$ & $\begin{array}{l}\text { Cyclical } \\
\text { in-work } \\
\text { poverty }\end{array}$ & $\begin{array}{l}\text { Impoverished } \\
\text { non- } \\
\text { employment }\end{array}$ \\
\hline \multirow{2}{*}{ Black men $^{1}$} & $-0.37^{* * *}$ & 0.1 & -0.22 & $0.36^{*}$ & 0.32 \\
\hline & 0.11 & 0.13 & 0.11 & 0.16 & -0.18 \\
\hline \multirow[t]{2}{*}{ Hispanic men ${ }^{1}$} & 0.06 & -0.07 & -0.16 & -0.07 & 0.01 \\
\hline & 0.22 & 0.29 & 0.26 & 0.38 & 0.42 \\
\hline \multirow{2}{*}{ White women $^{1}$} & -0.22 & $0.49^{* * *}$ & $-0.30^{*}$ & -0.13 & $0.70^{* * *}$ \\
\hline & 0.13 & 0.14 & 0.14 & 0.22 & 0.2 \\
\hline \multirow[t]{2}{*}{ Black women ${ }^{1}$} & $-0.88^{* * *}$ & 0.17 & $-0.50^{* * *}$ & $0.60^{* * *}$ & $0.97^{* * *}$ \\
\hline & 0.13 & -0.14 & 0.13 & 0.17 & 0.18 \\
\hline \multirow{2}{*}{ Hispanic women ${ }^{1}$} & -0.19 & $0.62^{*}$ & $-0.69^{*}$ & -0.86 & $0.85^{*}$ \\
\hline & 0.27 & 0.27 & 0.34 & 0.6 & 0.33 \\
\hline \multirow[t]{2}{*}{ Years of education } & $0.12^{* * *}$ & $0.05^{*}$ & $0.08^{* * *}$ & -0.05 & $-0.11^{* * *}$ \\
\hline & 0.02 & 0.02 & 0.02 & 0.03 & 0.02 \\
\hline \multirow{2}{*}{ Management, Professionals ${ }^{2}$} & $0.95^{* * *}$ & $-0.67^{* * *}$ & $0.51^{* * *}$ & $-0.44^{*}$ & $-1.78^{* * *}$ \\
\hline & 0.13 & 0.17 & 0.14 & 0.21 & 0.25 \\
\hline \multirow[t]{2}{*}{ Technical, Sales Admin. Support ${ }^{2}$} & $0.99^{* * *}$ & $-0.53^{* * *}$ & $0.46^{* *}$ & $-1.02^{* * *}$ & $-1.78^{* * *}$ \\
\hline & 0.13 & 0.15 & 0.14 & 0.24 & 0.22 \\
\hline \multirow{2}{*}{ Service $^{2}$} & $0.30^{*}$ & $-0.72^{* * *}$ & $0.27^{*}$ & $-0.37^{* *}$ & $-1.72^{* * *}$ \\
\hline & 0.13 & 0.13 & -0.12 & 0.13 & 0.16 \\
\hline \multirow{2}{*}{ Farming, Fishing, Craft, Production ${ }^{2}$} & $0.83^{* * *}$ & $-0.74^{* * *}$ & $0.52^{* * *}$ & $-0.89^{* * *}$ & $-2.36^{* * *}$ \\
\hline & 0.12 & 0.15 & 0.12 & 0.17 & 0.26 \\
\hline \multirow[t]{2}{*}{ Operators, Fabricators, Laborers ${ }^{2}$} & $0.52^{* * *}$ & $-0.31^{*}$ & $0.56^{* * *}$ & $-0.36^{*}$ & $-1.58^{* * *}$ \\
\hline & 0.12 & 0.12 & 0.11 & 0.14 & 0.19 \\
\hline \multirow{2}{*}{ Experience } & -0.01 & -0.01 & $0.02^{*}$ & 0.02 & -0.02 \\
\hline & 0.1 & 0.1 & 0.1 & 0.1 & 0.1 \\
\hline \multirow[t]{2}{*}{1 child $^{3}$} & -0.1 & $-0.41^{* *}$ & $0.34^{* *}$ & 0.09 & 0.1 \\
\hline & 0.12 & 0.13 & 0.12 & 0.17 & 0.15 \\
\hline \multirow{2}{*}{2 children ${ }^{3}$} & -0.24 & $-0.41^{* *}$ & 0.1 & 0.19 & -0.17 \\
\hline & 0.13 & 0.13 & 0.12 & 0.17 & 0.15 \\
\hline \multirow[t]{2}{*}{$3+$ children ${ }^{3}$} & -0.14 & $-0.51^{* * *}$ & $-0.30^{*}$ & 0.05 & -0.06 \\
\hline & 0.13 & 0.13 & 0.13 & 0.17 & 0.15 \\
\hline \multirow[t]{2}{*}{ Single never married ${ }^{4}$} & 0.09 & -0.18 & 0.16 & -0.09 & 0.11 \\
\hline & 0.13 & 0.13 & 0.13 & 0.16 & 0.15 \\
\hline \multirow[t]{2}{*}{ Separated $^{4}$} & 0.08 & -0.02 & 0.19 & -0.13 & -0.13 \\
\hline & 0.12 & 0.12 & 0.12 & 0.15 & 0.15 \\
\hline \multirow[t]{2}{*}{ Left parental home } & $-0.58^{* * *}$ & $-0.44^{* *}$ & $0.84^{* * *}$ & 0.09 & -0.12 \\
\hline & 0.15 & 0.16 & 0.21 & 0.22 & 0.19 \\
\hline Mills Ratio & $0.44^{* * *}$ & $0.24^{* *}$ & 0.05 & -0.14 & -0.13 \\
\hline & 0.08 & -0.09 & -0.09 & 0.12 & 0.1 \\
\hline Year of birth & $-0.04^{* * *}$ & 0.01 & 0 & $0.03^{* *}$ & $0.06^{* * *}$ \\
\hline & 0.01 & 0.01 & 0.01 & 0.01 & 0.01 \\
\hline Age & -0.01 & 0.01 & -0.04 & 0 & $0.05^{*}$ \\
\hline & 0.02 & 0.02 & 0.02 & 0.02 & 0.02 \\
\hline Time & 0.06 & 0.17 & $0.25^{* *}$ & 0.1 & -0.11 \\
\hline & 0.09 & 0.01 & 0.09 & 0.12 & 0.12 \\
\hline $2+$ earners in the household 5 & -0.11 & -0.07 & 0.11 & 0.06 & 0 \\
\hline & 0.06 & 0.07 & 0.07 & 0.08 & 0.09 \\
\hline Num. events & 870 & 754 & 939 & 491 & 591 \\
\hline Num. obs. & 6033 & 6033 & 6033 & 6033 & 6033 \\
\hline Missing & 472 & 472 & 472 & 472 & 472 \\
\hline Num. subjects & 2630 & 2630 & 2630 & 2630 & 2630 \\
\hline
\end{tabular}

Note: Sig.: ${ }^{* * *} \mathrm{p}<0.001,{ }^{* *} \mathrm{p}<0.01,{ }^{*} \mathrm{p}<0.05$; standard errors in italics. Reference categories: ${ }^{1}$ White men, ${ }^{2}$ Military or out of the labor force, ${ }^{3}$ Childless, ${ }^{4}$ Married; ${ }^{5}$ One earner in the household. Source: PSID. 
Figure B1 Competing risk Cox model for the probability of leaving in-work poverty through one of the five pathways (ref. Black men)

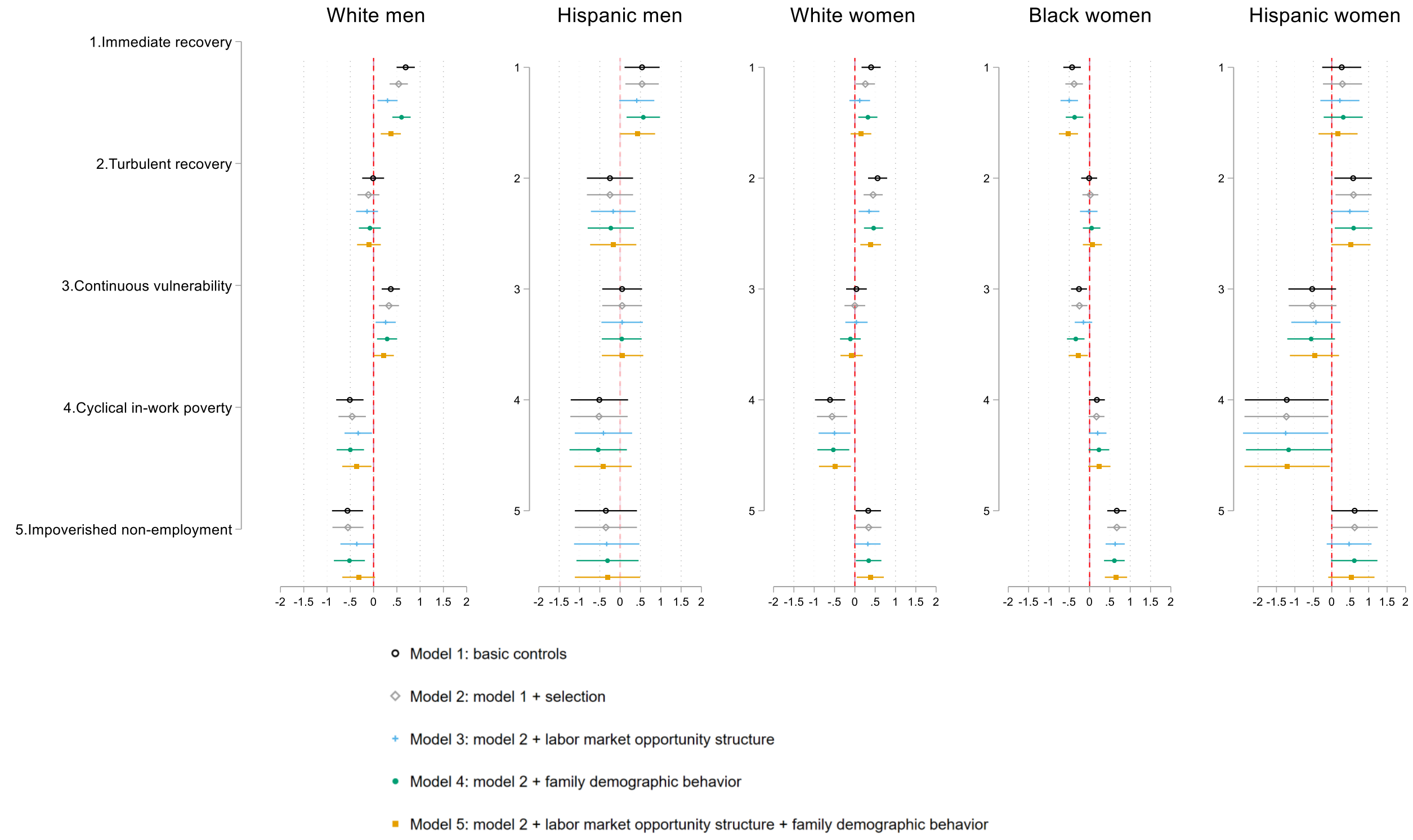

Note: Unstandardized coefficients and 95\% confidence intervals; All models are adjusted for number of earners in the household, birth year, age, time. Source: PSID. 
Figure B2 Competing risk Cox model for the probability of leaving in-work poverty through one of the five pathways (ref. Hispanic men)

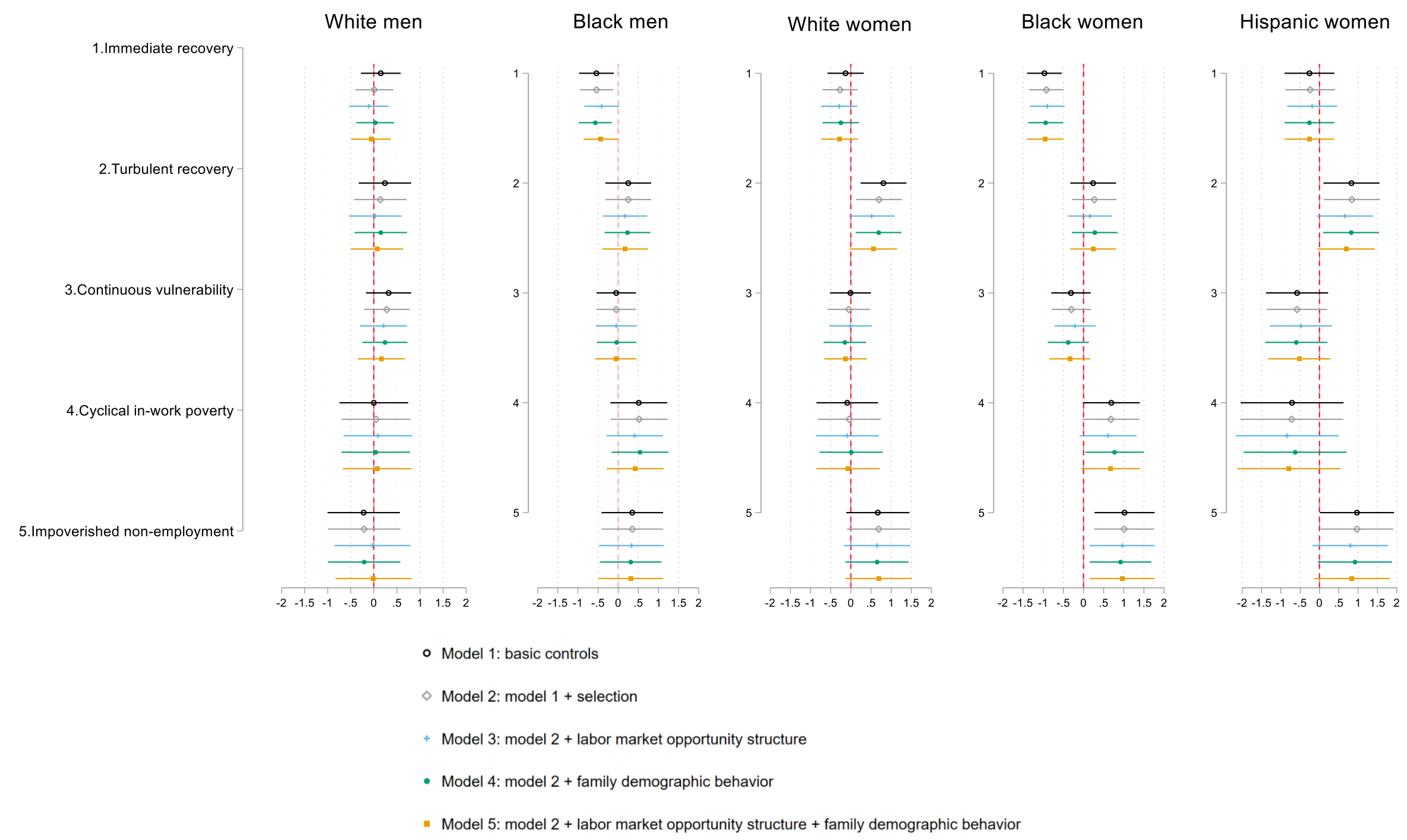

Note: Unstandardized coefficients and 95\% confidence intervals; All models are adjusted for number of earners in the household, birth year, age, time. Source: PSID. 
Figure B3 Competing risk Cox model for the probability of leaving in-work poverty through one of the five pathways (ref. White women)

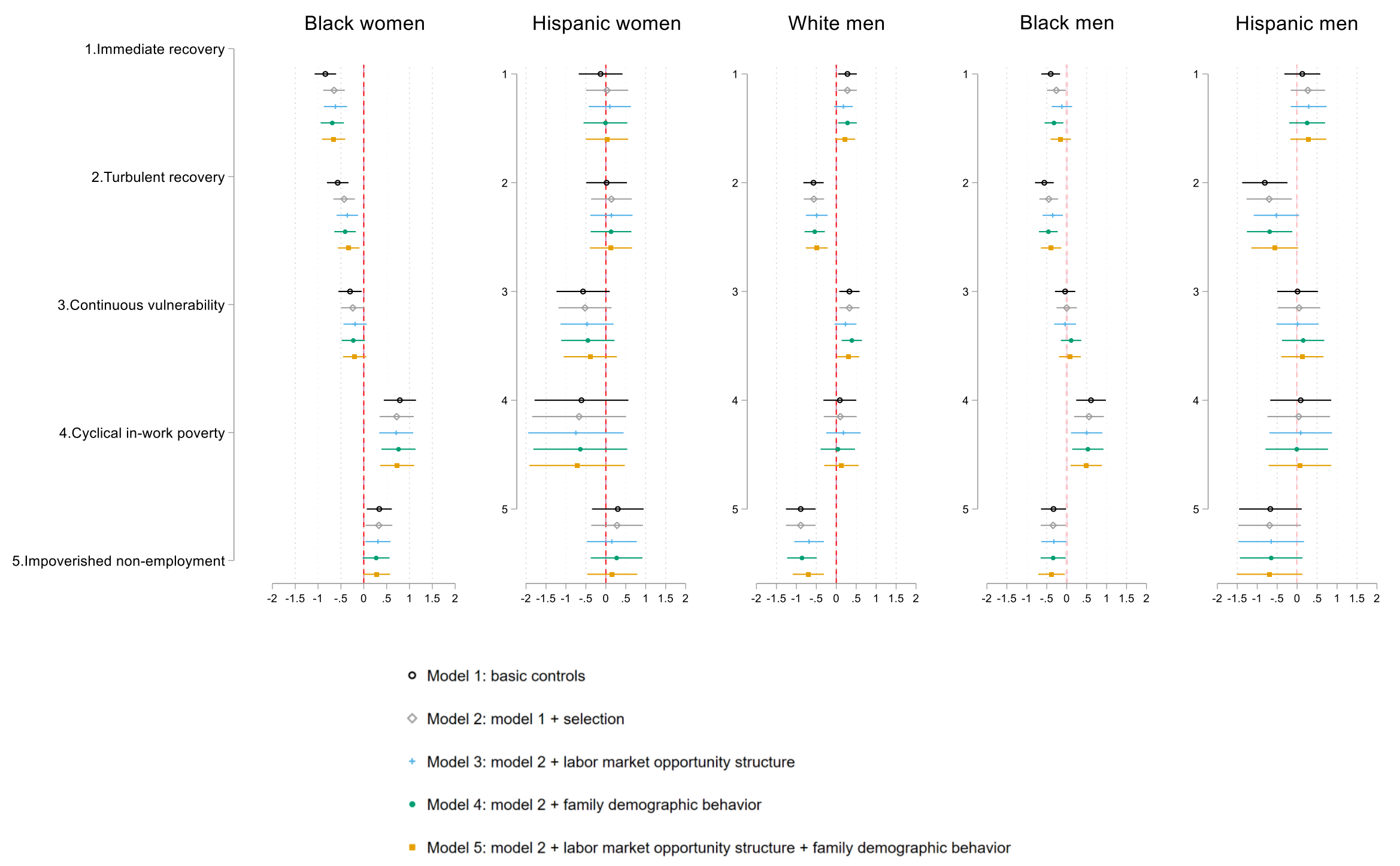

Note: Unstandardized coefficients and 95\% confidence intervals; All models are adjusted for number of earners in the household, birth year, age, time. Source: PSID. 
Figure B4 Competing risk Cox model for the probability of leaving in-work poverty through one of the five pathways (ref. Black women)
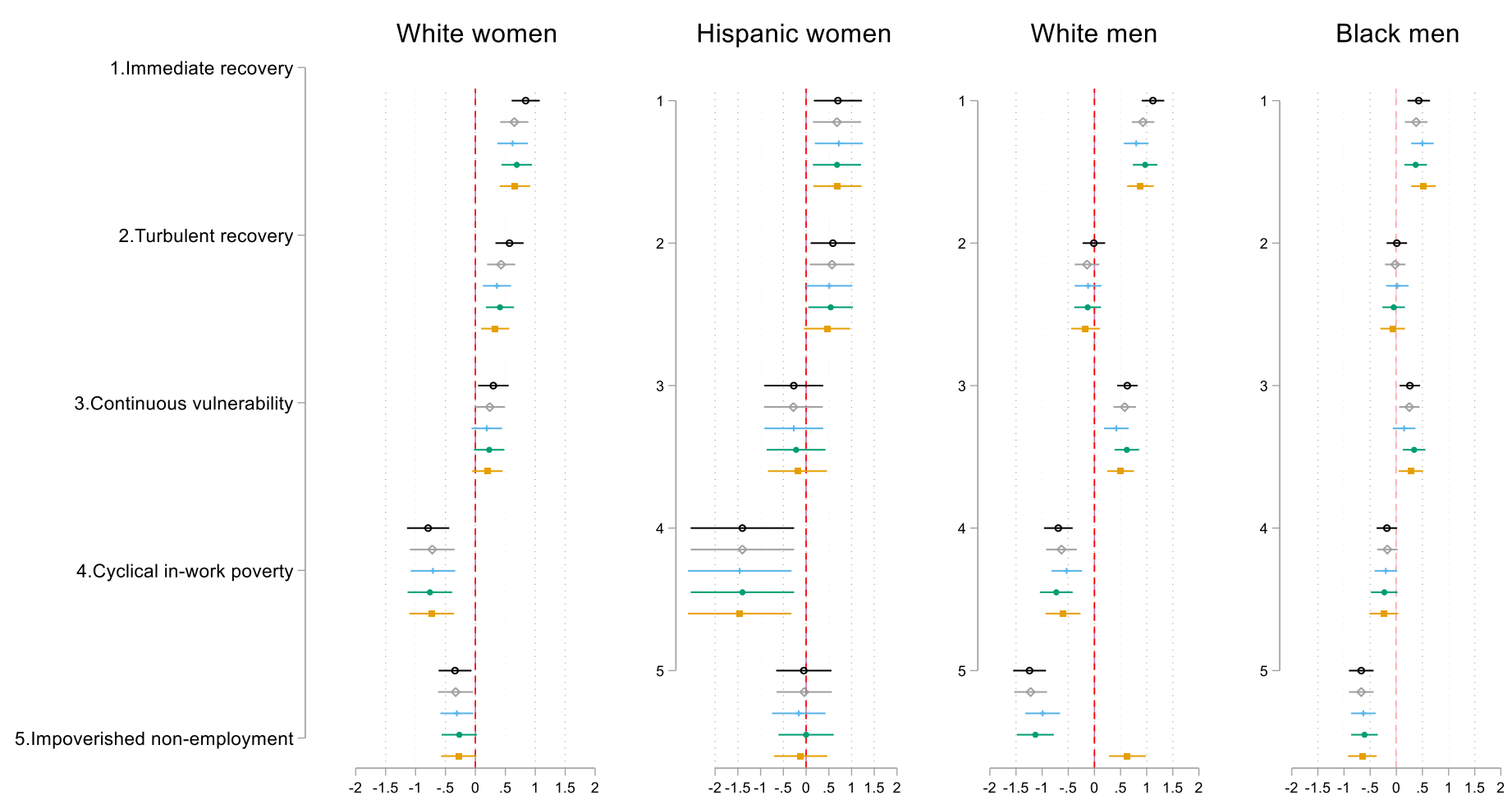

Hispanic men

- Model 1: basic controls

$\diamond$ Model 2: model $1+$ selection

+ Model 3: model 2 + labor market opportunity structure

- Model 4: model $2+$ family demographic behavior

- Model 5: model 2 + labor market opportunity structure + family demographic behavior

Note: Unstandardized coefficients and 95\% confidence intervals; All models are adjusted for number of earners in the household, birth year, age, time. Source: PSID. 
Figure B5 Competing risk Cox model for the probability of leaving in-work poverty through one of the five pathways (ref. Hispanics women)
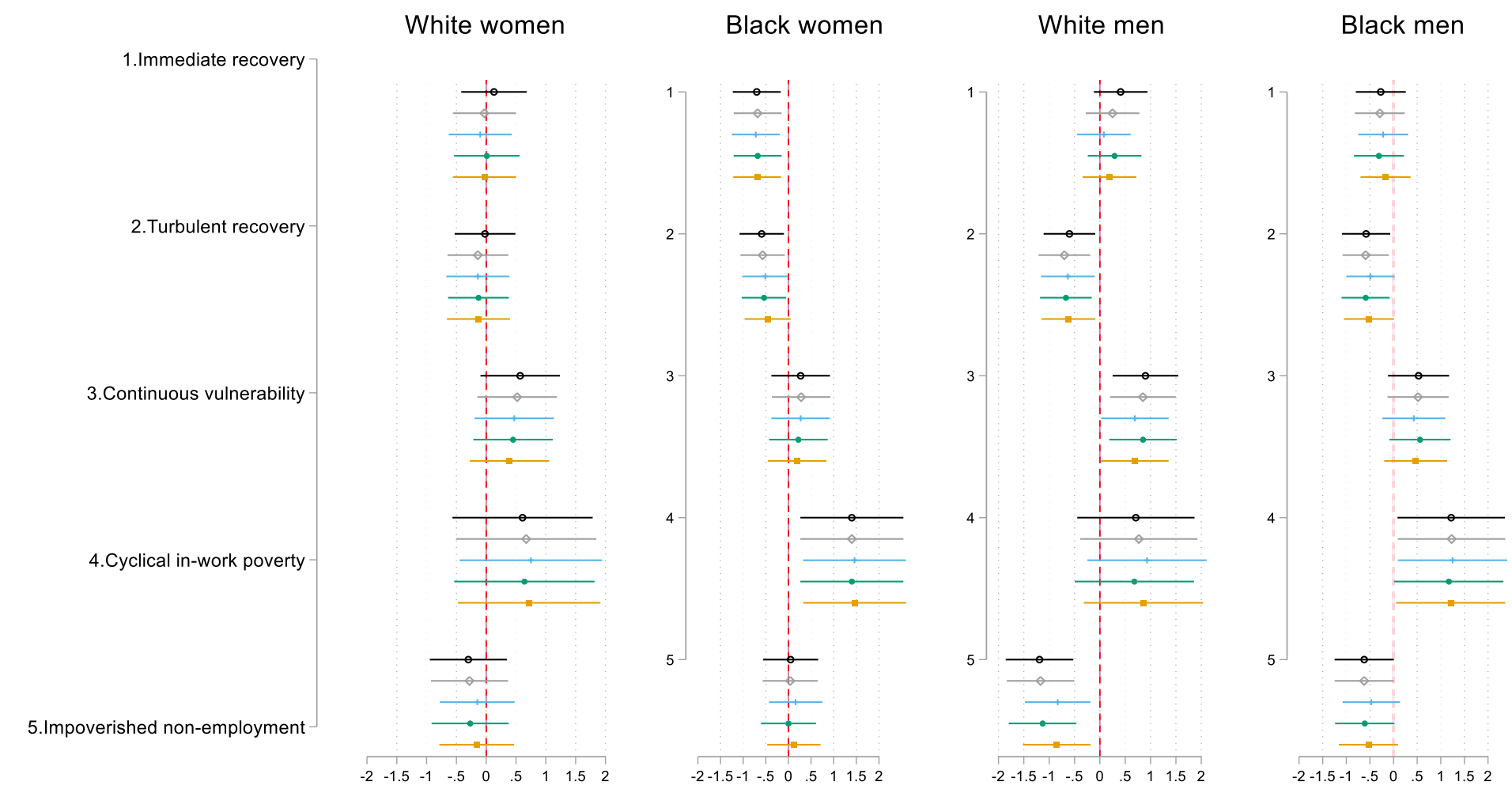

Hispanic men

○ Model 1: basic controls

$\diamond$ Model 2: model $1+$ selection

+ Model 3: model 2 + labor market opportunity structure

- Model 4: model 2 + family demographic behavior

- Model 5: model $2+$ labor market opportunity structure + family demographic behavior

Note: Unstandardized coefficients and 95\% confidence intervals. All models control for number of earners in the household, year of birth, age, time. Source: PSID. 


\section{Supplement C: Robustness Checks}

We conducted several robustness checks to ensure that our results are not driven by decisions on modeling or other factors. All results are available upon request.

a) We do not include weights that correct for selective sampling probabilities. However, we calculated attrition weights in two steps. We estimate inclusion probabilities, i.e. the probability of being observed in the next wave, using probit random effects models with a number of covariates, including the current and previous state variables, the average number of weekly hours worked over the past year, respondents' marital status, family size, birth year, age, and study. Note that we consider both item and unit non-response as non-observation. Second, the weight is calculated by cumulatively multiplying the inclusion weights across observed waves, where the first wave has an inclusion probability of 1 . Therefore, the first person-year has a weight of 1 , the second personyear is one multiplied with the inclusion probability, and so forth. Our analyses are robust to the inclusion of these weights.

b) We do not hold our sample size constant in the models presented in the manuscript, as we deleted cases listwise depending on missing on the covariates progressively included in the models . We decided to present results where we allow sample sizes to vary across models to have the most precise standard error estimates possible and to retain as many observations as possible at each step. We nonetheless preformed all analyses with a constant sample size to ensure that changes in point estimates are attributable only to the inclusion of new covariates and not changes in variance. Overall estimates are very similar to those presented in the manuscript (results available upon request). As expected, some coefficients do become statistically insignificant once the sample size is reduced. 
c) The length of the subsequences was set to five years. We tested for more and less restrictive thresholds, namely four and six years after exiting in-wok poverty. In the first case, the time span appeared to be too short to identify mid-term falling back into in-work poverty and the clusters appear to be dominated by one single state instead of signifying dynamics over time. In the case of a wider observational window, six-years long sequences did not add qualitatively interesting information, especially with respect to the cost in terms of lower sample size due to the trade-off between the length of the subsequences and the possibility to keep in observations from younger individuals or individuals who are observed for a shorter period of time for other reasons.

d) We ran the cluster analysis as well as mixed effects competing risks cox hazard regressions on (i) other data sources (1979 and 1997 National Longitudinal Surveys of Youth, NLSY79 and NLSY97), (ii) other data sources (NLSY79 and NLSY97) pooled with PSID, and (iii) PSID using additional waves between 1998 to 2015 where household income is measure on a biannual rather than an annual basis. Robustness checks (i) and (ii) served respectively the general purpose of increasing our confidence in the results based on PSID only and the more specific aim of extending our substantive consideration to a historical period between 1997 and 2011. In fact, the NLSY79 consists of respondents born between 1957 and 1964 first interviewed in 1979. The NLSY97 sample consists of 8, respondents born between 1980 and 1984 first interviewed in 1997 and collected on a biennial basis starting in 1994 for the NLSY79 and 2011 for the NLSY97. With minor deviations in the prevalence of the subsequences in the clusters, the pathways identified and the estimates remain consistent: although the three surveys contribute differently to the extraction of subsequences that are then assigned to each cluster, the same pathways can be found when clustering the subsequences from each survey independently. Robustness checks (iii) extends the observational window until 2015 by 
using biannually collected information on household income between 1998 and 2015 as it was annual. The main difference is represented by a higher number of subsequences in cluster 2 "Turbulent recovery", which is relatively advantageous pathway out of in-work poverty. The results of competing risks cox hazard regressions are highly consistent in the direction and the significance of the effects for all clusters, with the only (expected) exception of some coefficients for the now larger cluster 2 . The only notable difference with substantively interesting implications is that in these models Black women have compare to white men - a lower probability to exit in-work poverty via this relatively advantageous pathway and an even lower probability of following the more advantageous pathway (cluster 1) and a higher probability of following the most disadvantageous pathway (cluster 5). In other words, we can expect that if yearly data were available until 2015 , we could observe an increase in the overall prevalence of a relatively advantageous pathway out of in-work poverty, but that this would be enjoyed by some groups of workers only while other will be even more exposed to pathways at higher risk of social exclusion. 